University of San Diego

Digital USD

Theses

Theses and Dissertations

Spring 5-11-2015

\title{
Leadership Cultural Values of United Arab Emirates-The Case of United Arab Emirates University
}

\author{
Ebtesam Ali Alteneiji \\ University of San Diego
}

Follow this and additional works at: https://digital.sandiego.edu/theses

Part of the Leadership Studies Commons, and the Sociology Commons

\section{Digital USD Citation}

Alteneiji, Ebtesam Ali, "Leadership Cultural Values of United Arab Emirates-The Case of United Arab Emirates University" (2015). Theses. 2.

https://digital.sandiego.edu/theses/2

This Thesis: Open Access is brought to you for free and open access by the Theses and Dissertations at Digital USD. It has been accepted for inclusion in Theses by an authorized administrator of Digital USD. For more information, please contact digital@sandiego.edu. 
Leadership Cultural Values of United Arab Emirates-The Case of United Arab Emirates University

by

Ebtesam A. Alteneiji

A Thesis submitted to the faculty of University of San Diego

In partial fulfillment of the requirements for the degree

Master of Arts in Leadership Studies

May 2015 


\title{
UNIVERSITY OF SAN DIEGO \\ SCHOOL OF LEADERSHIP AND EDUCATION SCIENCES
}

\author{
CANDIDATE'S NAME: Ebtesam A. Alteneiji
}

TITLE OF

THESIS:

LEADERSHIP CULTURAL VALUES OF UNITED ARAB EMIRATES-THE CASE OF UNITED ARAB EMIRATES UNIVERSITY

APPROVAL:

\begin{tabular}{ll}
\hline Afsaneh Nahavandi, Ph.D. & Chair \\
\hline Zachary Gabriell Green, Ph.D. & Member
\end{tabular}

DATE: $\quad$ May 11, 2015 


\begin{abstract}
UAE is a young country with a young population that has witnessed tremendous changes over the past decades. There has not been much research about the cultural values of the UAE in generational perspectives, and there have been rapid changes. Therefore, this study aimed at exploring systematic changes in leadership cultural values among the older and the younger generations of the United Arab Emirates. The author utilized Hofstede's (VSM08) instrument to survey undergraduate students, administrators and faculty at UAE University.

The study found no significant differences between the younger and older generations' tolerance to unequal distribution of power (power distance), fear of the unknown (uncertainty avoidance), quality of life (feminism), tight knit social framework (individualisms) and the exhibition of short-term orientation.

Surprisingly, participants in this study scored significantly lower on power distance, masculinity and uncertainty avoidance than those in Hofstede's original data that was collected 30 years ago. The specific characteristics of the represented sample, and the systematic value change were investigated as a possible explanation of the nation's indices, and low masculinity in particular. Empirically, wealth and Western influence emerged to be the primary factor for the registered index scores, and the study unveiled generational struggles in a traditional, yet largely Westernized society.
\end{abstract}




\section{Acknowledgments}

First and foremost, I want to thank Professor Afsaneh Nahavandi, my chair supervisor and mentor for her friendly guidance for the study of cross-cultural communication, and constant encouragement in making this research thesis a reality. I would like also to thank Prof. Zachary Green, my committee reader for his tremendous support and guidance over the past two years at the Department of Leadership Studies at the University of San Diego.

Words cannot express how grateful am I to my father, mother and sister Nouf for all of the sacrifices you made on my behalf, and for your dedication to lend a hand in this venture. This thesis would not have come to a successful complete without the kind cooperation of United Arab Emirates University's Vice Chancellor, Dr. Ali Al Noaimi, UAEU Teaching Assistant Office and College of Humanities and Social Sciences.

To you all, I owe you profound appreciation and gratitude! 


\section{Table of Contents}

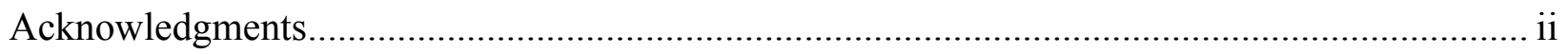

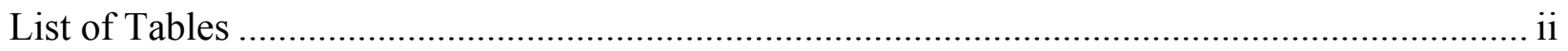

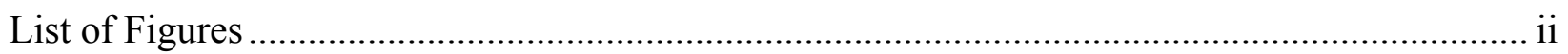

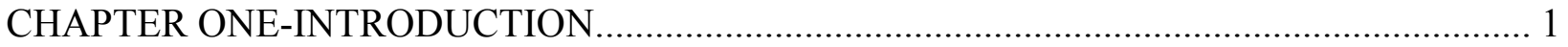

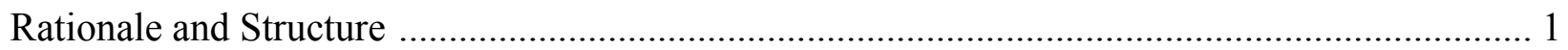

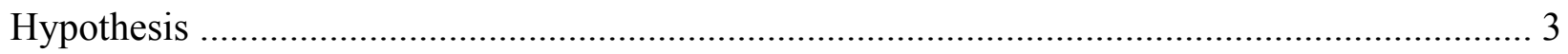

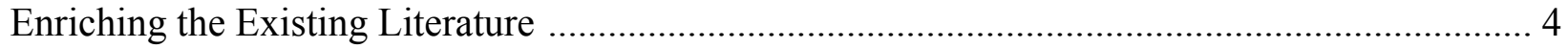

CHAPTER TWO: LITERATURE REVIEW ................................................................ 6

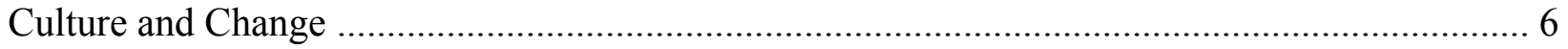

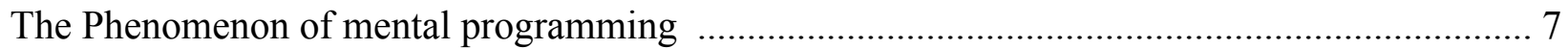

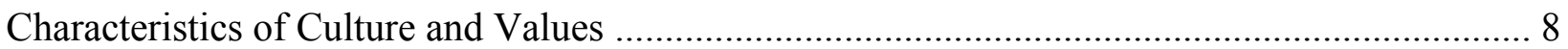

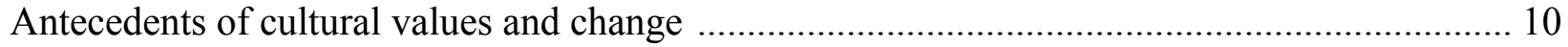

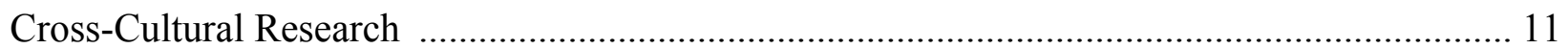

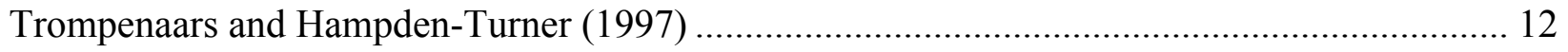

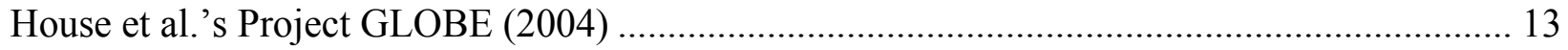

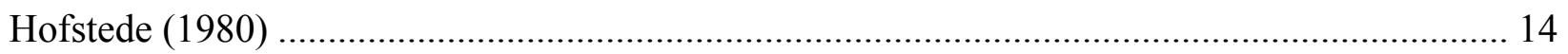

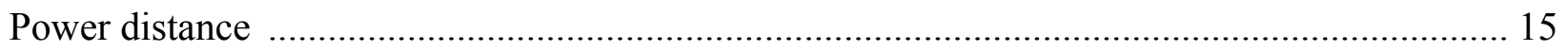

Individualism Individualism vs. Collectivism ................................................................ 18 
Masculinity vs. Femininity

Uncertainty Avoidance

Long-Term Orientation

Data Validation: Economic, Geographic, and Demographic Indicators

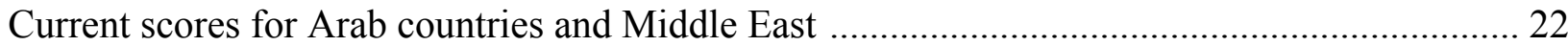

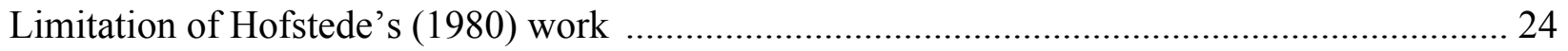

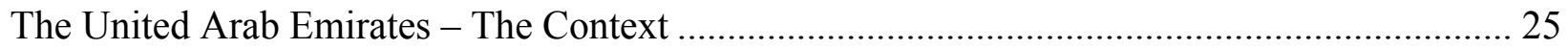

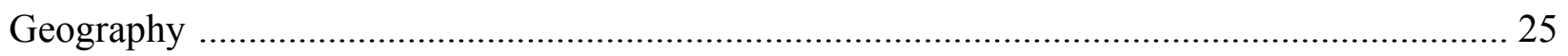

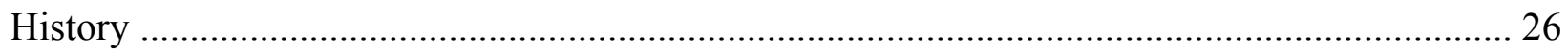

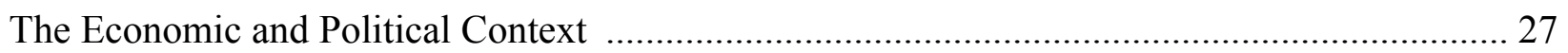

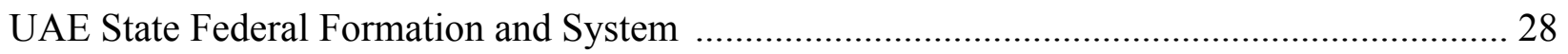

The political system of UAE Government …….................................................................... 30

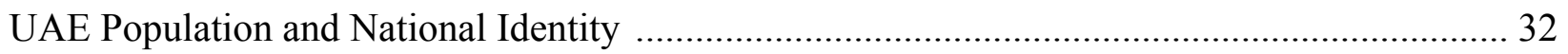

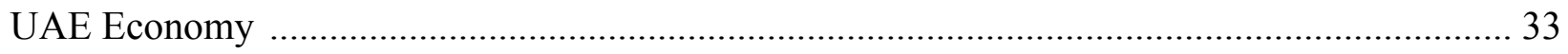

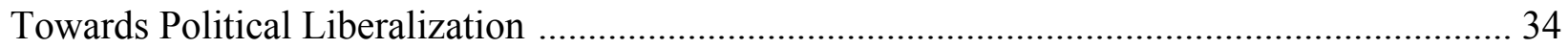

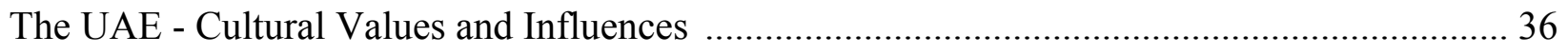

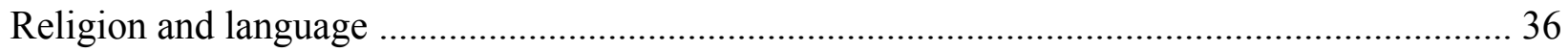

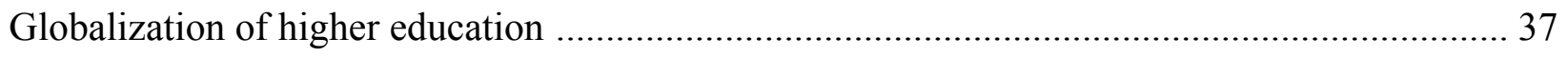

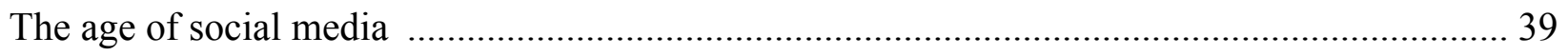

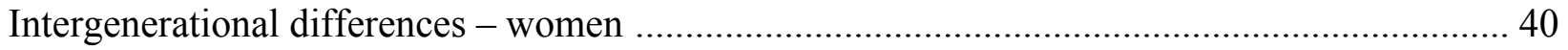




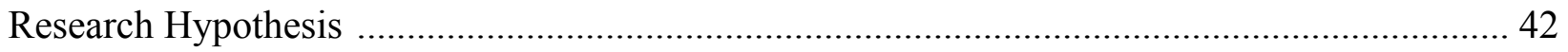

CHAPTER THREE-METHODLOGY AND RESULTS ......................................................... 46

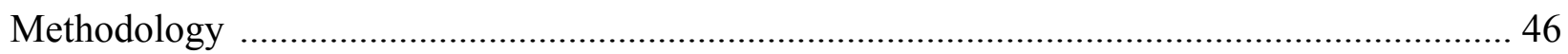

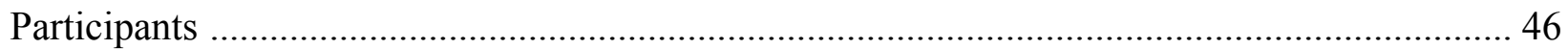

Demographic Characteristics of the Participants ………………................................................. 47

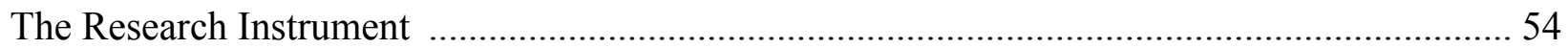

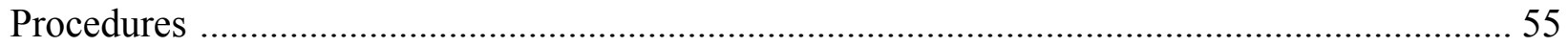

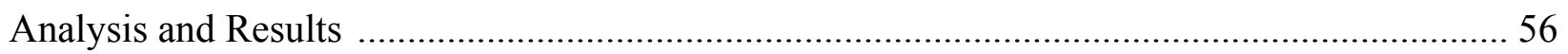

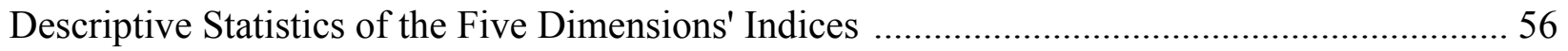

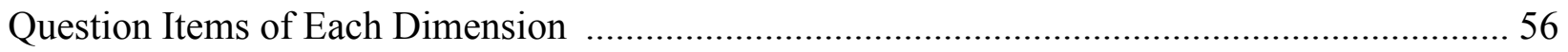

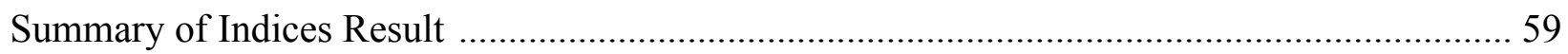

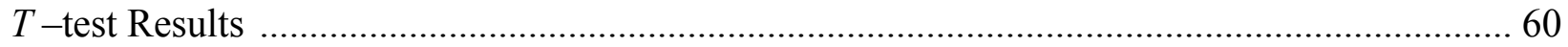

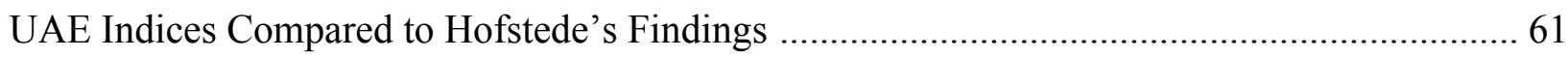

CHAPTER FOUR-DISCUSSION, LIMITATION AND FUTURE DIRECTION ...................... 63

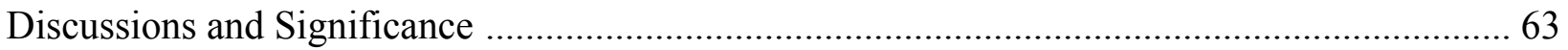

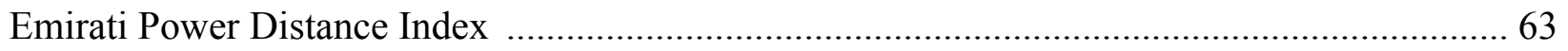

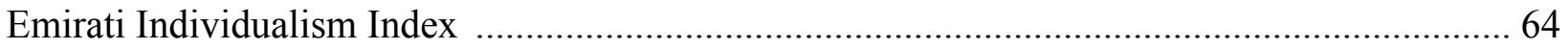

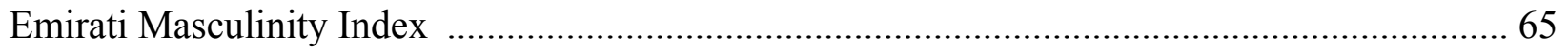

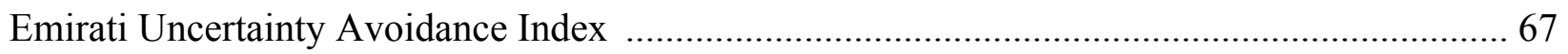


Emirati Long-Term Orientation Index

Limitations

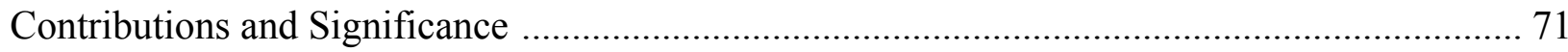

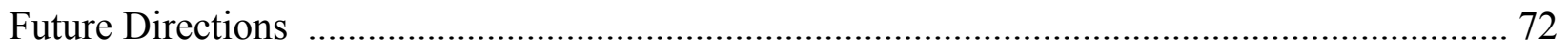

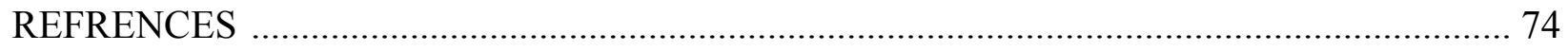

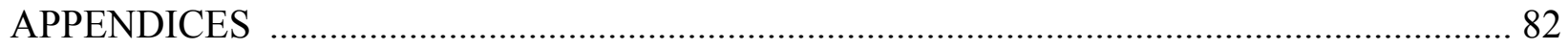

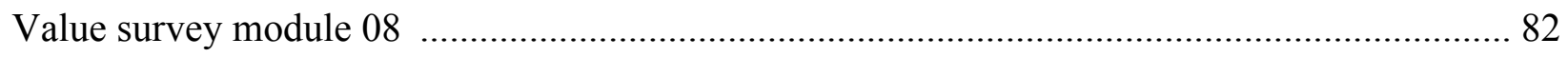

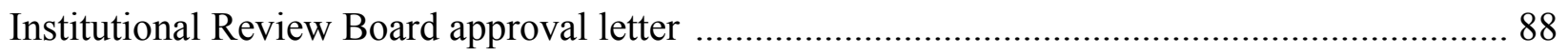

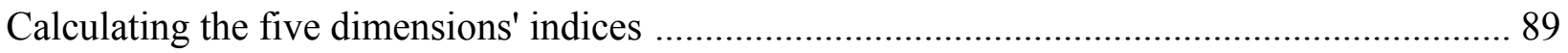




\section{List of Tables}

Table 1. Scores of the Arab-Speaking countries and Middle East...................23

Table 2. Sample distribution according to gender............................47

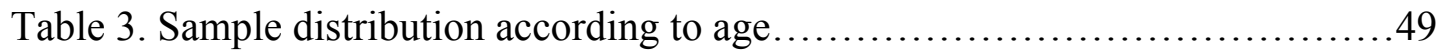

Table 4. Sample distribution according to Emirates..........................50

Table 5. Sample distribution according to job type............................52

Table 6. Illustrates the mean of each question...............................57

Table 7. Comparison of generations on the five dimensions....................60

Table 8. T-test Results.................................................61

Table 9. Study Results Compared to Hofstede's Findings.......................62 


\section{List of Figures}

Figure 1. The "Onion": manifestations of culture at different levels of depth ........................... 9

Figure 2. Hofstede's nine geographic, demographic and economic predictors ........................ 22

Figure 3. United Arab Emirates geographical map .............................................................. 26

Figure 4. UAE historical population 1960 - 2015 ............................................................ 32

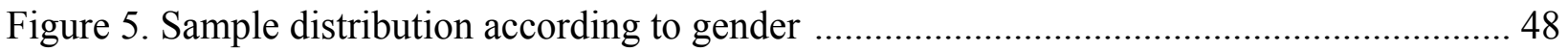

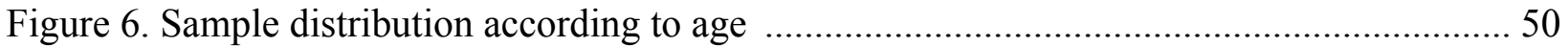

Figure 7. Sample distribution according to Emirates ............................................................. 51

Figure 8. Sample distribution according to job type ....................................................... 53

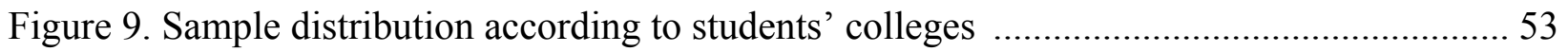

Figure 10. Sample distribution according to faculty and administration ................................ 54 


\section{CHAPTER ONE \\ INTRODUCTION}

\section{Rationale and Structure}

The overall aim of the research study is to illustrate changes in leadership cultural values among the older and the younger generations of the United Arab Emirates. This will be attained by analyzing how the leadership cultural values are manifested among the older and the younger generations of the UAE as measured by Hofstede's Value Survey Module (VSM08) study questionnaire. The goal was to examine generational differences or similarities and explore reasons for such differences. The results will also be compared to previous findings from Hofstede's work 30 years ago on the five dimensions of power distance, individualism, masculinity, uncertainty avoidance and long-term orientation. Moreover, the data may enable the researcher to identify some cultural patterns of UAE society, and captures systematic changes of value and generational orientations in fast developing economies as is the case in the Gulf region and UAE society in particular.

Mills (2008) notes that only one-third of Emirati high school graduates in the UAE go to branch campuses of American and other foreign institutions in the country. About 35,000 students attend UAE University, Zayed University and Higher Colleges of Technology, where school tuition is fully paid for by the UAE government, and educational systems are based on American higher education systems. UAE University is the country's flagship institution that is largely Westernized, and enrolls more than 14,000 students who come from the seven emirates of the nation. Thus, UAE University tends to provide a representative sample of the different populations of the emirates while also representing a Western cultural profile. 
This study updates the work of Hofstede (1980) that examined cultural values of 117,000 IBM employees in 50 nations around the globe in the period of 1966-1974. UAE data was collected during the country's first stages of formation as a federal nation of the seven emirates. Until the mid of 1960s and after the announcement of British departure in 1968, UAE was known as merely an inhospitable arid desert with a mainly poor population of Bedouin tribes, traders and pearl divers (Al-Majaida, 2002) that used to obtain basic traditional education of Islamic teachings and mathematics. On December 2nd 1971 UAE was formed as a country of six emirates until Ras Al-Khaima joined in 1972.

Initially, when Hofstede undertook his study between 1966 and 1974, UAE, as a federal nation, was still forming and normalizing before the petrodollars of oil revenues were pumped into the larger society, which later led to a dizzyingly rapid pace of evolution of a very different world in the desert land. It is within this context that this thesis seeks to present new input through the analysis of the leadership cultural values of the older and younger generation of the UAE. It suggests that the necessity to add the knowledge base to update the current cultural dimensions data on the UAE and Gulf countries in general to examine the systematic value change and the fragility of culture in young and fast-developing societies.

UAE presents unique geographic, economic, demographic, social and political characteristics and indicators, which are explained in a detailed discussion in the following chapter on the contextual literature of the UAE. In the last decades, UAE has gone under dramatic changes, and have been rapidly transformed from an impoverished traditional society into a highly modern internationalized and largely westernized country. With vast oil resources; economic changes and modernization have come very fast to the lifestyle and cultural identity of this largely traditional Muslim society. The younger generation has grown up in this traditional, 
yet westernized society but their parents and ancestors were reared in a very different culture. These dramatic changes were a major stimulant for the researcher to undertake the current research study in studying different generations of the UAE.

In addition, culture is expected to change over a period of time due to the combined influences that come from nature and man-made forces in an environment. The current sociopolitical events in the Arab region, demographic imbalance in the Gulf countries, trade, economy, westernized education, and exchanges of mutual experiences, all have profound influences in modifying and altering a culture over a period of time. Added to that are the socialization of new generations that will carry and alter some of the value as time goes by. Hofstede (2001) himself indicates that value changes gradually, but slowly overtime (p. 233).

\section{Hypothesis}

The researcher hypothesizes that the younger generation of the UAE will score lower on power distance, uncertainty avoidance and masculinity dimensions when compared to the older generation, while both generations will score similarly on the individualisms and long-term orientations dimensions of Hofstede. Therefore, the study aims to find generational positions of the two generations of the UAE in order to further understand the leading factors behind the country overall indices on the five dimensions compare to Hofstede's old data of IBM. Srnka (2004) argues that culture needs to be understood as a multidimensional phenomenon that compromises more than just a nationality of nation. In fact, there are very few studies that look into generational differences and how cultural change may differ among generations before calculating the total indices for the country and generalize the scores on the nation or regions that compromises the same characteristics of the studied culture. However, this research study explores generational differences and similarities on Hofstede's five dimensions of culture, and 
compares the current nation's indices represented by the study sample to Hofstede's dated data on the UAE. Thus, the main reason for utilizing Hofstede's methods and applying them to different generations within the UAE University is to gain a deeper understanding of systematic value change, and to examine the limitation of "made in America" approach to understand traditional Islamic values of Arabs and fast developing nations in the Arabian Gulf.

\section{Enriching the Existing Literature}

Ideally, the findings from this research can enrich the body of knowledge on UAE cultural values, which might be also relevant and applicable in the other five GCC countries: Saudi Arabia, Kuwait, Qatar, Bahrain and Oman as they have some historical and cultural ties that characterize them as fast-developing economies, Islamic societies and Westernized nations. Moreover, the results of this study will mirror the cultural profile of highly Westernized institutions in these countries such as higher education systems and private corporations in the region. It will also unveil generational struggle to adopt in traditional wealthy nations that are largely influenced by the West to foster their economic competitiveness; and the desire to preserve the Arabic Islamic values of the Bedouins, which are indicating some changes on the surface of cultural fabrics of these nations. Furthermore, it is important for the UAE government to understand any changes on cultural values of its citizens to adopt new policies and initiatives that further the country's development with a conscious attention to the newly adopted values or changes in the cultural mindsets of the nation in order to sustain prosperity in the country.

The researcher herself is born and raised in the UAE, and is a graduate of UAE primary and higher education cultural systems. The researcher's value system is shaped through her upbringing with the influences of Emirati heritage and traditional values, Islamic beliefs, her education in governmental Westernized institutions and interactions with different expatiates in 
the country. Since, the author is part of the UAE younger generation who enjoyed growing in the sudden wealth, she points out the importance of exploring cultural changes in the life of different generations within the UAE to generate a deeper understanding for how natural and man-made forces shape and modify a culture in the context of rapid economic and cultural transformations, and how generations may differ in responding to cultural changes. Therefore, the current exploratory research study attempts to examine and identify changes in leadership cultural values among the older and the younger generations of the United Arab Emirates through utilizing Hofstede's framework of cultural dimensions. 


\section{CHAPTER TWO: LITERATURE REVIEW}

\section{Culture and Change}

This chapter reviews the existing literature and the major research studies on the concepts of culture and cultural values with a particular focus on Geert Hofstede's work and research about cultural values in the United Arab Emirates (UAE).

Culture is a dynamic reflection of a system or a society which; constantly affects the behavior of all individual members of a particular society, interacts with the environment, is learned and can be adjusted and passed from generation to generation.

Kluckhohn (1951) defines culture as a way of thinking, feeling and reacting, which are acquired and transmitted by symbols that forms the distinctive achievements of human groups and their attached values (Hofstede, 2001, p. 9). Similarly, Kroeber and Parsons (1958) views culture as transmitted patterns of values, ideas and symbolic systems that shape human behavior, and the created content is produced through human behavior (Hofstede, 2001, p.9). In addition, Clifford Geertz (1973, p. 89) defines culture as a fabric of inherited conceptions and means by which people interact, perpetuate and expand their knowledge to interpret their experience and guide their action towards life (p. 145). Finally, Geert Hofstede (2010) defines culture as the "collective programming of the mind which distinguishes the members of one human group from another" (p.10).

Kluckhohn views the cyclic nature of culture as a way of thinking that influences the behavior of individuals with a focus on the method of learning and transmission. Kroeber and Parsons' definition of culture is similar to Kluckhohn's description in regarding the method of cultural transmission, but they suggest the use of 'social systems' to designate the relational 
system of social interaction among individuals. Clifford Geertz refers to culture as a mean of communication and interpretation, and not the 'mental software of the mind'. Hofstede's definition is a shortened one that implies almost everything in the above mentioned definitions and covers more complex and inherent programming of a social environment. In this research study, the author will adhere to Hofstede's definition of culture as the most comprehensive and cited definition in the study of culture.

In the last decades, culture is often referred to as a set of values adopted by a particular group that define the life style of that group; cultural values translated into norms, beliefs, morals, and are reflected in laws and practices of the society (Adler, 2002). These common practices and experiences of members of collectives bring about shared identities, beliefs, values, motives and meanings. These are manifested as history, language and ideological belief systems: religion and political one that are transmitted from across age generation. Social scientists attribute these set of parameters of collectivities that differentiate the collectivities from each other in meaningful ways (House \& Javidan, 2004, p. 15).

\section{The Phenomenon of mental programming}

In the $14^{\text {th }}$ century A.D the great Muslim Scholar Ibn Khaldudn in his famous book AlMuqaddima shed the light on different characteristics of nomads and sedentary peoples, including mindsets, education, social and political behavior, and architecture. He mentions the phenomenon of mental programming: Indeed, the mind in its original state is ready to absorb any influence, good or bad. As Mohammed has said: every child is born in a natural state. It is his parents who make him into a different state of ideology (Hofstede, 2001, p.13). Therefore, the belief systems and behaviors of children is a reflection of adults' 'mental software' in the group. 
Geert Hofstede (2001) views Mental Programs as social systems that only prevail because human behavior is to some extent predictable. It is assumed that each person carries a certain amount of mental programming that is stable over time, which is not directly observable and are manifested as behavior, words or deeds that reflect the national culture of a country (p.2). Accordingly, Hofstede (2001) believes that cultural transmission involves intergenerational learning and absorption of internal learning and external forces of change: trade, conquest, economical or political dominance, and technological breakthroughs. Moreover, Inkeles (1977) finds continuity in the American national character ever since the descriptions by Crevecoeur dating from 1782. This is particularly interesting because the United States is a country of immigrants; it reveals itself with amazing clarity that culture is learned, not born (p.34).

\section{Characteristics of culture and values}

The conceptual framework of culture implies that values are the building block that forms the basis of any culture; and a standard for socially acceptable norms that shape people's formation of attitudes (KO, 1994). Geert Hofstede (2001) believes that values are invisible until they become evident in behavior, but culture influences behavior through its manifestations: symbols, heroes, rituals, and values, as well as language, ideology, rituals, myths, and ceremony (Groeschl and Doherty, 2000; Karahanna et al., 2005). In Figure 1 cultural characteristics are pictured as layers of an onion around a core that consists of values. 


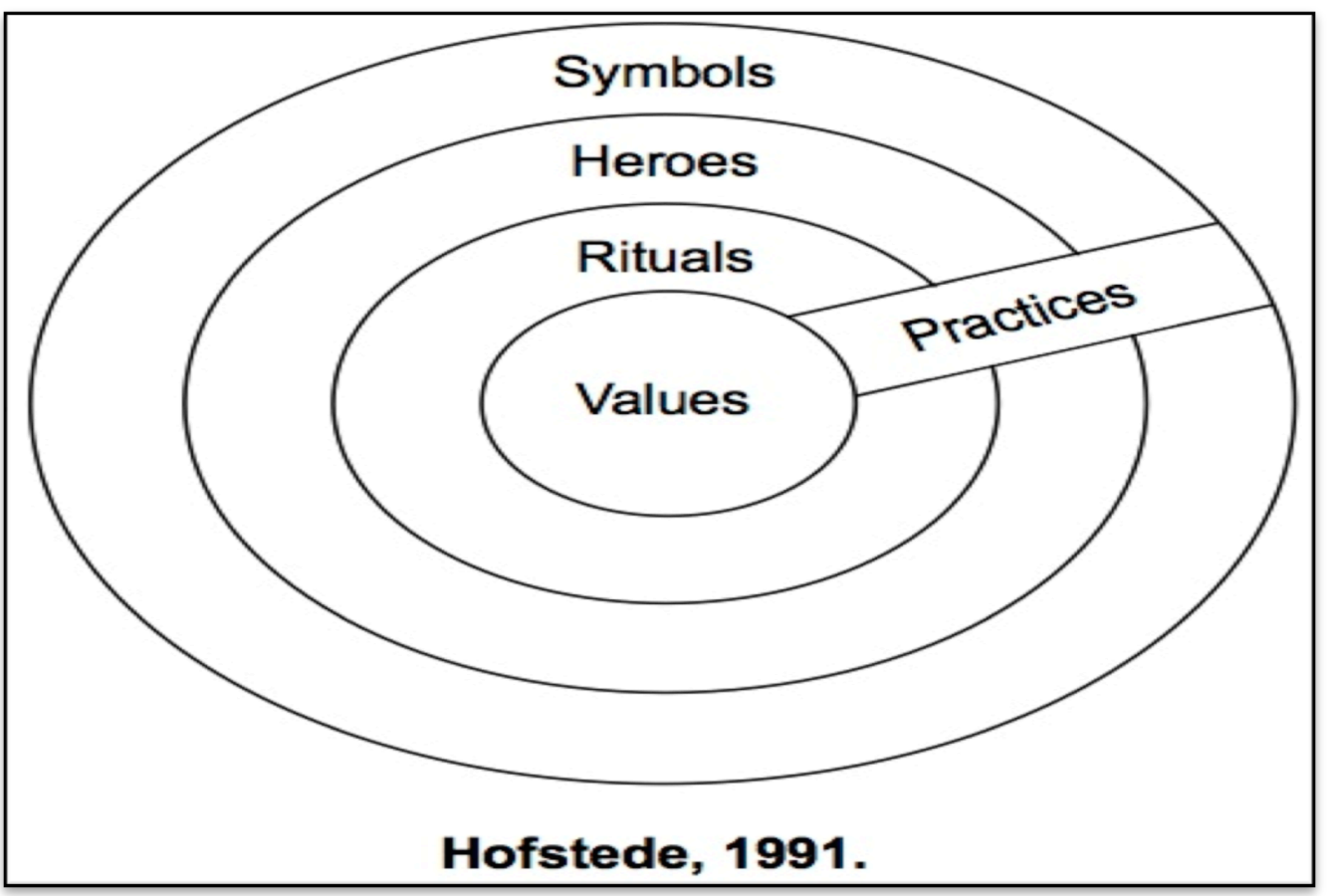

Figure 1: The "Onion": Manifestations of Culture at Different Levels of Depth. Adopted from http://www.unfoldconflicts.nl/defriending/

Looking back at the definitions of culture presented earlier, two main components are values and practices. Values, from a scholarly point of view, are intimately connected to the moral and ethical codes that are widely accepted in the society and organization of belief concerning what is a desirable behavior, right or wrong action. Karahanna et al. (2005, p. 35), and Meed (1994) refers to value as relationships among abstract categories that are characterized by strong affective components and imply a preference for a certain type of action: good, right and desirable (p.35). Similarly, Hofstede (2001) views values as judgmental standard of one's behavior and the one of others that prefers certain states of affairs over others.

This value system is relatively stable in nature but can change over time reflecting changes in culture as well as personal experience. However, values also change quickly through 
extreme circumstances e.g. war, social movements and economic development (Karahanna, et al, 2005).

Another important factor that shapes culture is attitudes. De Mooij (2002) defines attitudes as a lasting general evaluation of people, objects and issues. Attitudes are expressed values that dispose an individual to act and react in a certain manner and norm. Thus, attitudes are a state of mind that is developed through social identity process and charged with emotions (Bohner \& Wanke, 2002, p.4). Everyday we are exposed to countless attempts at changing or reinforcing our attitudes through personal communication, the mass media or the Internet. While forming attitudes, personal characteristics and events' perception lead to assimilation or rejection. Family, educational system, racial beliefs and mass media are the primary sources of attitudes (Bohner \& Wanke, 2002, p.4).

\section{Antecedents of cultural values and change}

Hofstede $(2001 ; 2010)$ believes that cultural values originate from both internal and external forces operating in national cultures and each society. He argues that our world is changing and cultural change can be fast for the outer layer of the onion diagram, labeled practices and slow for the onion's core, labeled values.

The internal factors are labeled 'ecological' and contain aspects of the nation's history, geography, demography, gene pool, economy, urbanization and technology. Changes also come from outside, in the form of forces of human beings: climate changes or environmental hazards, and forces of man: trade, conquest, economical or political dominance, internationalization of media and technological breakthroughs (Hofstede, 2001, p.34). Therefore, any changes in culture will have direct impacts on motivations, attitudes and values of individuals in each society. 
Our societies are deeply influenced by recent events in our evolution, and our predications of the future are not expected because "news and innovations can travel the world in days, if not seconds" (Hofstede \& Minkov, 2010, p.476). Thus, what are the factors that affect and change culture?

Theory of modernization is one of the major perspectives in the sociology of national development and underdevelopment since the 1950s. Modernization is an explanation of societal transformation from traditional or underdeveloped nations to modern, and Westernized nations through the process of economic development and change in social, political, and cultural structures (Armer \& Katsilis, 2001). Armer and Katsilis (2001) stressed that the sociological concept of modernization should not be confused with becoming current or "up to date," but rather defines particular connect and process of societal transformations in the course of national development. The essence of modernization theory suggests that advanced industrial technology not only produces economical growth in developing nations, but also structural and cultural changes that comes from advanced Westernized societies.

\section{Cross-Cultural Research}

.Hofstede (2001) argues that the survival of humankind will be largely dependent on the ability of people who think differently to act collectively. He emphasizes that international collaboration suggests some understanding of how others' thinking differs from ours. He further discusses the importance of understanding and exploring how nationality predisposes our thinking and is therefore not an intellectual luxury (p. XV). Furthermore, House, et al. (2004) point out that cultural differences are disappearing, technology is changing the way we communicate, and globalization is changing the way we trade and interface. Thus, a deep understanding of invisible cultural differences that exist across the globe is one of the main 
contributions the social sciences can make to practical policy makers in governments, organizations, and institutions-and to ordinary citizens (p.5).

Cross-cultural research explores, explains, and understands the similarities and differences among individuals of different culture, which stems from the increasing need to define culture and nationality and how it influences the national culture of a nation. In addition to the aforementioned, most of the previous studies on cultural studies focus on the West and are conducted by Westerners. This is particularly significant since the $21^{\text {st }}$ century that is well known as the global world (McFarland, Senen, \& Childress, cited in House, et al., 2004, p. 10).

\section{Trompenaars and Hampden-Turner (1997)}

Trompenaars and Hampden-Turner (1997) carried out a large research study focusing on explaining cultural diversity in business after spending 10 years researching the preferences and values of more than 46,00 business executives in 40 cultures around the world. In their book Riding the waves of culture (1997), Trompenaars and Hampden-Turner developed a model that identifies seven value orientations to distinguish people from one culture compared with another (Trompenaars \& Hampden- Turner, 1997): Universalism versus Pluralism, Individualism versus Communitarianism, Specific versus Diffuse, Neutral versus Affective, Inner versus Outer Directed, Achieved versus Ascribed, Sequential versus Synchronic Time.

These dimensions are partly validated but academically not very well accepted" (Adler, 2002). Dahl (2004) explains that the Trompenaars model could be used to understand the people from different background, but that it lacks a concrete numerical schema that could help researchers to use it as a reference point to test cultures empirically. 


\section{House et al.'s Project GLOBE (2004)}

The research project "GLOBE" (Global Leadership and Organizational Behavior Effectiveness research program) is a worldwide, multi-method programmatic research project conceived by Robert House in 1991. The comprehensive research was designed to "explore the fascinating and complex effects of culture on leadership, organizational effectiveness, economic competitiveness of societies, and the human condition of members of the societies studied." To address these issues, the extensive cross-cultural study obtained responses on 735 questionnaire items of 17,300 middle mangers from 951 organizations functioning in 62 societal cultures. The cultural aim of the project was to primarily explain different preferences in leadership styles; however the collected data was also used to analyze national culture and organizational culture. GLOBE grouped 62 societal cultures into 10 clusters (i.e. Anglo (7), Nordic Europe (3), Eastern Europe (8), Sub-Saharan (5), Southern Asia (6), Latin Europe (6), Germanic Europe (5), Latin America (10), Middle East (5) and Confucian Asia (7). As a result of this research effort, GLOBE project presents 62 society scores on 9 major dimensions of culture (Adler, 2002). House et al. (2012) noted the importance of distinguishing between cultural values and practices; in the form of social practices (as is) and in the form of social values (as should be). The nine cultural dimensions are power distance, uncertainty avoidance, humane orientation, institutional collectivism, in-group collectivism, assertiveness, gender egalitarianism, future orientation, performance orientation.

GLOBE research project is highly recognized and citied in the last decade as well as criticized. The significance of the study comes from its big network of 170 native researchers who collected and analyzed data of their cultures (Brewer \& Venaik, 2010). Aside of the significance of the study, Hofstede (2010) argues that GLOBE project is relatively a small 
sample, and using the 'organizational culture' term leads to confusion and obscurity. Brewer and Venaik (2010) reference Maseland and van Hoorn (2009) in their analysis of GLOBE study's failure, in which they indicate that in seven of the nine dimensions, there is a negative correlation between social practices (as is) and social values (as should be) due to the limitations of selfreport questionnaires (Brewer \& Venaik, 2010).

\section{Hofstede}

Christie, Won, Stoeberl \& Baumhart (2003) state that Hofstede is one of the most influential scholars in the field of international management to develop an empirically validated typology, which affects human behavior and business organizations. His most notable work on cultural dimensions is if not the most, one of the most regarded, cited and applied studies in this area. Sivakumar and Nakata (2001) denote that only in the decade between 1987 and 1997, Hofstede's word was cited more than 1,100 times. His first best-known book Culture's Consequences (1980) reveals his comprehensive research on how values in the workplace are influenced by culture.

Hofstede is a native of the Netherlands and earned his doctorate in the field of social psychology in his hometown. In 1966, he undertook a big project involving the major multinational corporation, IBM. In the project, he surveyed IBM employees at all levels from unskilled workers to top managers in 50 developed and developing nations including United Arab Emirates. IBM employees completed 117,000 questionnaires that were administered in the language of each country; a total of 20 languages were employed. The primary difference among the respondents was culture; all of them were otherwise similar because they were carefully selected for other characteristics such as age, sex, and job category, and all worked for the same corporation. His approach was unique in such a way where he could make comparisons across 
countries. The actual sample size was 40 , which produced a list of approximately 100 countries with scores on Hofstede's five cultural dimensions.

The empirical results of the data cover the four basic problem areas predicted by Inkeles and Levinson twenty years before, which are now defined as dimensions of cultures in the IBM data. In other words, a dimension is an aspect of a culture that can be measured relative to other cultures. The four dimensions are power distance (PDI), uncertainty avoidance (UAI), individualism-collectivism (IDV), and masculinity- femininity (MAS). Confucian Dynamism (CDI) was developed later, and not included in the initial study. Hofstede (2010, p.54) explains that each of these terms existed already in some parts of the social sciences, and they seem applicable to the common basic problems worldwide that each dimension stands for. He further elaborates that the primary factor in distinguishing country from another is the nationality, which made the effect of nationality differences in people's responses stand out unusually clearly.

Hofstede (2010) brings attention to the popular management literature on leadership that often forgets that leadership can exist only as a complement to 'subordinates' and states that authority survives when it is matched by obedience (p.61-62). Comparative research studies investigating leadership values from one country to another demonstrate that the observable differences exist in the minds of both leaders and those led, but often the statements obtained from those who are led are a better reflection of the differences than those obtained from the leaders because we are better observers of our bosses' behavior than of ourselves.

Power distance (PDI). Power Distance Index is defined as the extent to which the less powerful members of institutions and organizations expect and accept the unequal distribution of power within a country. Institutions are the basic elements of society, such as family, the school, and the community; organizations are the places where people work. Therefore, power distance 
is described based on the value system of the less powerful members. The way is distributed is usually explained from the behavior of the more powerful members, the leaders rather than those led. In high power distance cultures, power hierarchy is obvious, and individuals respect their superiors without questioning their authority (ex. UAE, Malaysia, Panama). In low power distance cultures, individuals tend to favor personal responsibility and autonomy. The power is shared and well dispersed. It also suggests that society members view themselves as equals. Low power distance implies greater equality and empowerment (ex. Austria, New Zealand). One of the aspects in which United Arab Emirates differs from United States is the way each society handles inequality. For instance, physical and intellectual capacities, wealth, power and status may or may not go together. In some societies, successful athletes, artists and scientists enjoy status, but rarely they hold political power. In this dimension, the UAE (1984) scored 90, which means that Emriati accept a hierarchical order in which everybody has a place with no further justification. Hierarchy in the UAE culture is reflected as inherent inequalities, centralization, autocratic leadership style, and subordinates' expectation to be told what to do (p.58).

In large PD culture, children are expected to be obedience to their parents and independent behavior is not encouraged in their behaviors. Respect is an important virtue that lasts through adulthood and children are expected to support their family financially and practically. In small PD culture, children are more less treated as equal as soon as they are able to act. Children learn to say "No" and are expected to contradict their parents. The need for independence is supposed to be a major component of adults' mental software.

According to Hofstede (2010), it is so hard to give an answer to the extent an education system can contribute to changing a society because the pair parent-child is replaced by the teacher-student role in the school. In large PD education system, the parent-child inequality is 
perpetuated by a teacher-student inequality that caters the need for dependence well established in student's mind. On the other hand, small PD educational process is known as student-center system with a premium on student initiatives; students are expected to be creative and find their intellectual paths. Small PD countries spend the majority of their education budget on secondary schools more than university-education level.

Parents, teachers, mangers and rulers are all children of their cultures; in a way they are programs of their followers and their behavior can be studied if one also understand the mental software of their off-springs, students and subordinates, according to Hofstede (2010).

Ideas travel so fast to another countries via exportation and importations with no regards for the values context in which these ideas were firstly developed. These ideas are not limited to politics, but it is visible strongly in the domains of education and business especially in the modern nations in the developing world such as Oil Gulf Countries. Modern nations became so hungry for the US and European applications of management and leadership, in particular, after the economic success of United States in WWII, which viewed US as superior in this field. US leadership and management theories tend to be based on subordinates with medium-level dependence needs: not too low, and not too high. It is defined as participative management in which subordinates are involved in the decision-making.

We live in a century of unprecedented intensification of global communication where dependence on the power of others is decreasing gradually in some parts of the world. Political independence in forms of liberation and emancipation movements is becoming an attractive topic in MENA region. Countries can move to lower power distance level by advanced level of technology and education. 
Hofstede (2010) argues that there are some underlying factors associated with changes in power distance index (latitude, size of population, and wealth). For example, increases in national wealth may reduce power distance in modern nations, but only if it benefits an entire population. National wealth in itself stands for many other factors, each of which could be an effect and a cause of smaller power distances as follows: modern technology, more urban living, more social mobility and a larger middle class.

Individualism vs. Collectivism (IDV). The vast majority of people in our globe live in societies in which the interest of the group prevails over the interest of the individual, societies which we call collectivist. The early group in our life is always our family where we grow up and live together closely: not only with parents and siblings, but also sometimes with grandparents, uncles, aunts and servants, which is known as extended family. Children always view themselves as part of a "we" group, which is the major source of their identity and loyalty. At the other end of the spectrum, there is a minority of people in our world live in societies in which the interest of the individual prevail the interest of the group, which are called individualists. In these cultures, children always speak of themselves as "I" (Hofstede, 2010, p.91).

Individualism pertains to societies in which the ties between individuals are loose: everyone is expected to look after him- or herself and his or her immediate family. Collectivism as its opposite pertains to societies in which people from birth are integrated into strong, cohesive in-groups, which throughout people's lifetime continue to protect them in exchange for unquestioning loyalty (Hofstede, 2010, p.92). These concepts are the most popular among Hofstede's dimensions. As stated by Hofstede (2010) the individualisms versus collectivisms dimension is always confused with other dimensions, but it is the most regarded and cited in a 
variety of intercultural research. It is seen as the most easily grasped and frequently encountered when looking at other cultural behavioral patterns.

Basically, it refers to how individuals value themselves, their groups and organizations. High individualistic cultures tend to care more about self-actualization and career progress whereas people with high collectivistic values tend to value group benefits over their selfinterests (p.93). The UAE (Hofstede, 1980) is a collectivistic society with a score of 25 (p.95). This is manifested in fostering strong relationships with a close long-term commitment for fellow members of their group, and high preferences for a tightly knit framework and strong group cohesion.

Masculinity vs. Femininity (MAS). Masculinity versus femininity is an equally powerful dimension. Masculinity pertains to societies in which social gender roles are clearly distinct (i.e., men are supposed to be assertive, tough, and focused on material success whereas women are supposed to be more modest, tender, and concerned with the quality of life). Femininity pertains to societies in which social gender roles overlap (i.e., both men and women are supposed be modest, tender, and concerned with the quality of life (Hofstede, 2010, p. 140).

The dimension measures society’s goal orientation. A masculine culture refers to status derived from wages and position; a feminine culture focuses on human relations and quality of life. High MAS societies (ex. Slovakia, Austria, Venezuela) give a high importance to ambition, accumulation of wealth and power and there is a bold distinction between genders and their roles. In these cultures, males generally dominate a significant portion of the society while females are under domination. Low MAS countries (ex. Denmark, Norway, Sweden) do not reverse the gender roles. In a low MAS society, the roles are simply blurred; women and men are working together equally across many professions. Men are allowed to be sensitive and women 
can work hard for professional success. Society at large is more consensus-oriented and balanced. Hofstede (2010) indicates that this dimension is often neglected and appears to be confused with Individualism versus Collectivism dimension in other studies and contexts.

The UAE scored 50 in this dimension, and can be considered to be neither masculine nor feminine. It means that participants prefer men to have power and expect men to be more effective leaders in society and organizations (p.173).

Uncertainty Avoidance (UAI). Hofstede (2010) states that countries are different in their tolerance of the ambiguous and the unpredictable as the future is uncertain and we have to live it anyway. The Uncertainty Avoidance Index is defined as the extent to which the members of a culture feel threatened by uncertain or unknown situations; the extent to which a culture values predictability and tolerates uncertainty and ambiguity (p.191).

The UAI index mirrors the aversion of people to risk-taking and questions whether individuals require pre-set boundaries and clear structures in order to control nature. On the one hand, high UAI-scoring nations (ex. Greece, Belgium NI, Portugal, Arab Countries) try to avoid ambiguous situations whenever possible. They have strong traditions and rituals and tend toward formal, bureaucratic structures and rules. On the other hand, people in low uncertainty cultures (ex. Singapore, India, Sweden) are encouraged to find their path and truth, thus they are less rigid in their desire for instructions and rules. This dimension is often reflected in business negotiations, but it should not be confused with risk avoidance (p. 197).

In this dimension, the UAE scored 80, which means high preferences for avoiding uncertainty. This is reflected in rigid codes of behavior and beliefs, and intolerance of new ideas and behaviors (p.193). 
Long-Term Orientation (LTO). The dimension of "long term versus short term orientation (LTO)" is the result of Hofstede's cooperation with Michael Bond, who conducted the study in 23 countries in 1991 and added this dimension to the work of Confucius. It relates to Confucian dynamism and its time orientation. Hofstede (2010) describes LTO as:

Long-term orientation stands for the fostering of virtues oriented toward future rewards, and is characterized by persistence, ordering relationships by status and observing this order, thrift, and having a sense of shame. Its opposite pole, short-term orientation stands for the fostering of virtues related to the past and present, which is characterized by personal steadiness and stability, protecting your 'face', respect for tradition and reciprocation of greetings, favors, and gifts (p.239).

A high LTO characterizes countries (ex. Japan, South Korea, Hong Kong, Taiwan) in which they highly value the behaviors that influence the future such as perseverance, thrift and shame. These countries are often superstitious or based on many truths or faiths. Low LTO countries (ex. USA, Nigeria, Philippines, Saudi Arabia) on the other hand believe in absolute truth. They have high preferences for personal steadiness and stability, high respect for tradition and reciprocation of favors and gifts.

Data Validation: Economic, Geographic, and Demographic Indicators. Hofstede (2001) explores the relationships of dimensions with a number geographic, demographic, and economic indicators of the country. He uses nine of them to further validate findings and results: national wealth, past and present economic growth, geographic latitude, population size, population growth, population density, organizational size and relative organizational size (relative to the total inhabitants of the country) (see figure 2). For instance, the correlation of economic growth with population density reflects the influence of the fast-growing economies, in particular, East Asian economies. The correlation of theses indicators suggest causal chain for national differences, as it shows systematic relationships to the value systems of the survey data (p.68-69). 


\begin{tabular}{|c|c|c|c|}
\hline Code & Indicator & Definition & Source of Data \\
\hline GNP & Wealth & 1970 GNP/capita in $\$ / 10$ & World Bank Atlas, 1972 \\
\hline EGP & $\begin{array}{l}\text { Economic growth, } \\
\text { past period }\end{array}$ & $\begin{array}{l}1960-70 \text { average annual growth rate } \\
\text { of GNP/capita in } \% \times 10\end{array}$ & World Bank Atlas, 1972 \\
\hline EGF & $\begin{array}{l}\text { Economic growth, } \\
\text { following period }\end{array}$ & $\begin{array}{l}1965-90 \text { average annual growth rate } \\
\text { of GNP/capita in } \% \times 10\end{array}$ & $\begin{array}{l}\text { World Development Report, } \\
1992\end{array}$ \\
\hline LAT & Latitude & $\begin{array}{l}\text { Geographic latitude in degrees } \mathrm{N} \text { or } \mathrm{S} \\
\text { of country's capital city }\end{array}$ & Regular geographic atlas \\
\hline POP & Population size & $\begin{array}{l}\text { Decimal logarithm of } 1970 \text { number } \\
\text { of inhabitants in millions } \times 100\end{array}$ & World Bank Atlas, 1972 \\
\hline PGR & Population growth & $\begin{array}{l}1960-70 \text { average annual growth rate } \\
\text { of population } \times 10\end{array}$ & World Bank Atlas, 1972 \\
\hline PDN & Population density & $\begin{array}{l}\text { Population divided by area in square } \\
\mathrm{km} \text { (values for Hong Kong and } \\
\text { Singapore divided by } 8 \text { ) }\end{array}$ & $\begin{array}{l}\text { POP and Oxford Economic } \\
\text { Atlas, } 1972\end{array}$ \\
\hline ORS & Organization size & $\begin{array}{l}\text { Decimal logarithm of number of IBM } \\
\text { employees per } 1 / 1 / 1970 \times 100 \\
\text { (excluding manufacturing and } \\
\text { product development) }\end{array}$ & Company statistics \\
\hline ROS & Relative organization size & $\begin{array}{l}\text { Number of IBM employees divided } \\
\text { by number of inhabitants in } \\
\text { millions }\end{array}$ & POP and ORS \\
\hline
\end{tabular}

Figure (2): Hofstede's Nine Geographic, Demographic and Economic Predictors

Source: Culture's Consequences: Comparing values, behaviors, institutions, and organizations across nations — 2nd Ed (2001).

Current scores for Arab countries and Middle East. According to the below data (Hofstede, 2001), the Arab-speaking countries are Egypt, Iraq, Kuwait, Lebanon, Libya, Saudi Arabia, and the United Arab Emirates and have the following scores: 


\section{Table (1)}

Scores of the Arab-Speaking countries and Middle East on the four dimensions

\begin{tabular}{ccccccc}
\hline & $\begin{array}{c}\text { Arab-Speaking } \\
\text { Countries }\end{array}$ & UAE & Iraq & Lebanon & Iran & Turkey \\
& & & & & & \\
\hline Power Distance & 80 & 90 & 95 & 75 & 58 & 66 \\
Individualism & 38 & 25 & 30 & 40 & 41 & 37 \\
Masculinity & 52 & 50 & 70 & 65 & 43 & 45 \\
Uncertainty & 68 & 80 & 85 & 50 & 59 & 85 \\
Avoidance & & & & & & \\
\hline
\end{tabular}

Hofstede (2001) explains that the seven Arabic-speaking countries were treated as a one region because of a technical problem that inadvertently wiped the tape with the raw survey data and destroyed the data printouts as well. The only remained printouts data in the system pertained to the total region. He further suggests that the Middle East region is culturally less homogenous by any measure. Surely enough, some countries are wealthy with a high GNP, others are poor, some governments allow freedom of speech, other are so oppressive, some have extensive welfare systems, others cannot afford it or are not willing to distribute wealth freely (P.52). Therefore, the author believes that the abovementioned scores are simply insignificant and less representatives of the current changes in the region.

Hofstede (2001) notes that the system of national culture changes gradually because of external and internal forces. It has been more than three decades since Hofstede identified and measures the representative scores of the region. Given this time span, a cultural change is probable on the national culture of each country and in particular the Gulf Cooperation Council 
countries. The oil rich countries have gone under tremendous changes the past two decades with extensive welfare and healthcare systems and its correlation with the GNP, population size, political awareness and education.

Limitation of Hofstede's (1980) work. The most citied criticism of Hofstede's (1981) work is by McSweeney (2000) who argues that Hofstede's methodology is fundamentally flawed in which the sampling is sparse and unevenly distributed. McSweeney (2000) further claims that countries are not the proper unit of analysis because cultures are not necessarily bounded by borders. Moreover, he believes that Hofstede's (1981) work is fixated only on one high-tech US multinational corporation, and his data is derived from employees who may hold somewhat distinct values from the entire cultural system of a country. This argument is widely supported by other scholars. Graves (1986), Søndergaard (1994), Olie (1995) and Tayeb (2001) note that one company cannot fully represent a national culture. In addition, Hofstede (1998) points out that this is a limitation of the sampling method, and his main purpose was merely gauging differences between cultures. In his approach, he found some national differences despite the use of crosssectional analysis of one single corporation, which left the door open for national culture to explain the cultural differences in different parts of the world (Hofstede 1980).

Nasif et al. (1991) and Tayeb (2001) indicate that one common obstacle encountered by cross-cultural researchers is methodological simplicity. Methodologies are heavily based on ethnocentric pattern, and are presented by a single timeframe that provides misinterpretations, bias and inaccuracies (Nasif et al. 1991, 83-84). Furthermore, Tayeb (2001) argues that dimensionalization facilities comparisons across boundaries, but it simplifies the complex and dynamic nature of culture in a limited set of aggregate dimensions that do not represent the different communities within the national culture. Hofstede (1998) agrees and believes that 
additional dimensions should be added to his original work (p.481) and examples of that are: Long-term Orientation (Hofstede \& Bond, 1998) and the two additional dimensions of Minkov (2007).

In addition to the aforementioned, Tayeb (2001) points out that non-cultural factors such as media exposure, economic development and political influences are not considered in the design of many cross-cultural studies as they should be (p.91). Last but not least, Hofstede's work (1980) has been criticized by many researchers as outdated in the context of today's rapidly changing environments (Jones, 2007).

\section{The United Arab Emirates - The Context}

This section discusses the process of state formation in the UAE in historical perspective, and familiarizes the reader with the culture being researched by providing an overview of the UAE federation, geography, population, economy and politics, and the factors determining cultural influences and changes of intergenerational differences.

\section{Geography}

The United Arab Emirates is satiated in the Middle East, bordering the Gulf of Oman and the Arabian Gulf, between Oman and Saudi Arabia; it is on a strategic location along northern approaches to the Strait of Hormuz, a vital transit point for the world crude oil. The UAE is located on the southern coast of the Arabian Gulf from Khaur Udaid in the west to Ras Musandam in the northeast. The Emirate of Fujairh is located on the Gulf of Oman. The country covers a landmass of 32,300 square miles, about the size of South Carolina (Rugh, 2007, p. 3-4). The largest Emirate is Abu Dhabi, which accounts for 87 percent of the UAE's total area, and the smallest is Ajman. 


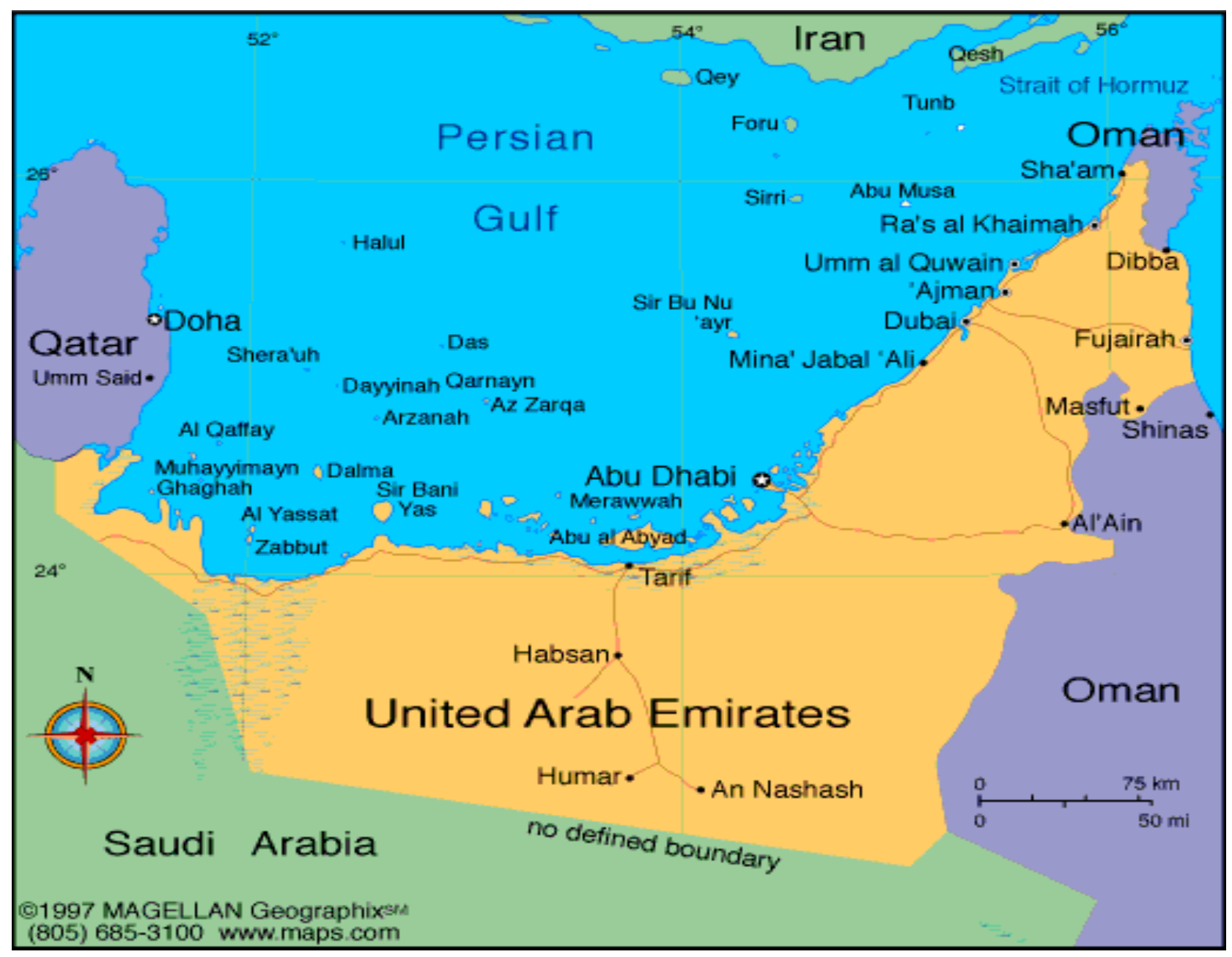

Figure (3): United Arab Emirates Geographical Map. Adopted from

http://www.infoplease.com/atlas/country/unitedarabemirates.html

\section{History}

Anthropologists refer to Arab tribes as being agnatic, patrilineal descent social groups who name themselves after an eponymous founder, in which they are linked by 'Asabiyyah', and are loyal to a chieftaincy or sheikh; which have the sense of collective responsibility over the protection of the group (Khoury \& Kostiner, 1990). Taking this concept into account, the UAE's pre-British tribal may be described as semi-nomadic Bedouins who coexisted with settled people to whom they were linked to each other by kinships, commercial or political ties (Cole, 2003, 
p.240). In this regard, Cole (2003) points out that today, 'Bedouin' refers less to a way of life than to an identity. The way of life was grounded in ecology and economy, the identity in heritage and culture (p.237)

\section{The Economic and Political Context}

Rugh (2007) pictures the harsh experience of the people and elemental existence that formed and sustained the tribal nature of society during the nineteenth and most of the twentieth century. Accordingly and throughout the time, each emirate had "a main settlement along the coast, and auxiliary settlements in scattered oases of the hinterland where inhabitants cultivated dates and a few crops. Tribal's access to sea and oasis engaged its members in mixed seasonal economy that include finishing pearling and trade between May and September. In spring people cultivate the earth and harvest the crops in the fall along with animal husbandry. (p. 6)

The Bedouin of the region were mainly camel-herding tribes that migrated in regular patterns throughout the year in search of water and pasture. Giving the nature of bad weather condition inland during the summer, the Bedouin abounded their nomadic activities where they left their families to embark in the boats of pearl merchants (Hawley 1970, p.201). Thus, the Bedouin revolved around the maritime activities and the pearling industry for a source of income. Seaman starts importing horses and dates from Basra and Bahrain, tobacco, carpets, sugar, and ghee from Persia and Makran in Baluchistan, rice, metal, and cloth from Bombay and coffee from Yemen. The tenth value of all imported goods was a good taxing income for the rulers (Rugh, 2007, p.7).

During that time, the rulers were largely dependent on merchants and the pearl industry's tax as their main source of revenue. Al-Sayegh (1998) notes that merchants were the key players in government decision-making process, and were the driving force behind development (p.87). 
Back in time, there was no fixed principle of succession, but they arguably followed a mix of personal interest and internal dispute with the Islamic principles of Ijtihad (interpretation) and Shura (consensus) to make a decision about the best ruler from members of different tribes. Although the sheikhs were in control of the territories, their authority was limited by tribal custom and the laws of Islam (Kour, 1991, p.187). As a result, politics in the sheikhdoms were organized around Ibn Khaldun's alignment of solidarities to gain dominance (Rugh, 2007, p.10).

Regarding leadership in the pre-British settings, a rough form of participatory leadership style was involved, and leaders were accessible and accountable. Maintaining political authority for a long period of time was very difficult if one sheikh failed to perform satisfactorily; loyalties were transferred to a new leader. Majlis was and still is a main component of Bedouin's life. It is a public audience where most chiefs listen to the concerns and discussions of elders who gather in their majlis. According to Rugh's (2007) description of majlis, it is a loosely organized system that allows anyone who wants to be heard to speak of his case before others. The system stresses loyalty to group, and value consensus, negotiation, and mediation (Rugh, 2007, p.10).

In the pre-oil sheikhdoms, "tribal proto states," as described by Gellner (Onley \& Khalaf, 2006, p.191), Dubai became the main commercial port of the Trucial States following the political instability in Persia and the decline of the port of Linga commerce. In addition, Dubai's strategic geographic location played a significant role in dramatic increase of trade growth in 1958 , in which the ruler of Dubai received customs duty of 4.52 percent on this trade (Hawley 1970, p.200).

\section{UAE State Federal Formation and System}

In the early 1950s, Great Britain made strides to secure maritime peace in the Gulf and bring states closer together (Hawley 1970, p.23). The British believed they were simply acting 
responsibly to protect maritime interests in the Gulf as they continued to claim non-interference in the internal affairs of local people until it was evident to everyone that the British were intensely involved. Two reasons were documented for Britain involvement in the region: they had a particular image of how the country should be ruled, and they played the role of paramount chief whose power brokering became crucial to the ambitions of lesser chiefs (Hawley 1970; Rugh, 2007; Zahlan, 1998).

As the oilfields were discovered elsewhere in the Gulf and suspicion grew that plenty were to be found in the region, Britain's interest shifted toward higher control in the Trucial States. Before oil was discovered in the region in 1958, commercialization agreements were signed between the rulers and the British to not grant any concession except to companies appointed by the British Government (Zahlan, 1998, p.17). During that time, Britain played a crucial role in promoting the idea of defining borders and of introducing new federal political system for the Gulf sheikhdoms. Along with the British attempts, Fenelon (1976) indicates that the rise of Wahhabi movement and the Iranian claims over the three islands under their control as well as the interest of other foreign powers in the region such as the United States made the sheikhs more aware of the importance of building strong alliances under a power of territorial basis rather than by a fluctuating tribal organization (p.21).

No serious movement toward federation was made, however, until 1968 when Britain announced that they would withdraw from bases east of Suez by 1971 . The news of Britain's intention triggered efforts to establish a wide Gulf federation to include Bahrain and Qatar as well as the Trucial States by Shiekh Zayed Bin Sultan Al-Nahyan, the Former President of The UAE who passed away in 2004. Shiekh Zayed had a great vision of big federation in the Gulf region, where he invited and led negotiation between the nine parties to form a union. However, 
differing interests made it unsuccessful. Zayed eventually convinced other rulers that they would benefit from a relationship with oil states. After three years of negotiations, six rulers signed the Provisional Constitution of the UAE in July 1971. Bahrain and Qatar refused to sign and Ras alKhaima joined two months later after the UAE became a federal state on December 2, 1972 (Hawley 1970; Rugh, 2007; Al-Fahim, 1995).

The political independence that the rulers had celebrated by means of British support and oil rents determined the supremacy that Abu Dhabi and Dubai gained over the other sheikhdoms because they had the largest oil reserves in the region. This was reflected in the provisional Constitution of 1971/1981, and tribal political structures were to a large extent superseded by territory and hierarchical authority (Tapper, 1990). As explained in the following paragraphs, the tendency has been toward centralization of power since the representation of the emirates in the federal institutions is established hierarchically with Abu Dhabi in the first place, followed by Dubai, Sharjah, Ras al- Khaimah, Fujairah, Ajman and Umm al-Qawain.

\section{The political system of UAE Government}

The Federal Supreme Council (FSC) is the highest executive and legislative authority of the federation. This body consists of the seven emirate rulers and is responsible for establishing federal policies and sanctioning legislation. There is no real separation of powers, and the rulers of each emirate take all decisions in the last instance, with the rulers of Abu Dhabi and Dubai having veto power on (FSC) decisions as expressed in article 49: The decisions of the Supreme Council on substantive matters are taken by majority of five of its members provided that Abu Dhabi and Dubai Emirates must be among the five members. The minority shall abide by the opinion of the majority. This is related to the abovementioned shift in the balance of power that 
took place from the Qawasim to the Bani Yas, as well as to the fact that Abu Dhabi, followed by Dubai, had the largest oil reserves.

The President is the head of state. He is elected by the FSC for a five-year term and appoints the Prime Minister, Deputy Prime Minister, and the Council of Ministers. A vice president is also elected by the FSC who can act on behalf of the president and exercise all forms of power in the absence of the president for any reason (Article 51). Although is not formally established in the article, the president has been always the ruler of Abu Dhabi, confirming the uncontested hierarchical supremacy of this emirate. The first president of the UAE was Sheikh Zayed bin Sultan Al Nahyan, who was succeeded by his son Khalifa bin Zayed in 2004.

The next institution on the power scale is the Council of Ministers, which is appointed by the President and headed by the Prime Minister. It consists of the Prime Minister, his Deputy and a number of Ministers (Article 55) and its members shall be chosen from among citizens of the Union known for their competence and experience (Article 56). It drafts decrees and laws but cannot approve them.

The Federal National Council (FNC) is a unicameral advisory and consultative body composed of forty members, which reviews legislation and proposes amendments but cannot enact or revise legislation and does not have veto power. It can make policy recommendations to the Cabinet, has the power to question any minister regarding ministry performance, and discusses the annual budget. Resembling the Federal Supreme Council and Council of Ministers in structure, the composition of the FNC established by the Constitution favors the emirates of Abu Dhabi and Dubai, with eight representatives each, while Sharjah and Ras al-Khaimah are represented by six each, and Fujairah, Ajman and Umm al-Qawain by only four each. 


\section{UAE Population and National Identity}

Peterson (2009) notes that nowadays UAE is home to an intriguing variety of religious, social, and ethnic minorities because of the massive economic growth in the region since the discovery of oil. In today's population, Emirati nationals have become a tiny minority, resulting from the dramatic demographic growth of workers who migrate to UAE to work in the enormous infrastructure and construction projects, which changes rapidly the composition and fabric of the UAE society. From a total of 89,608 thousands in 1960 to 10,083,014 million as of January 2015 (see figure 4), in which UAE nationals make up 11 percent of the total population, and the expatriates represent 95 percent of the UAE workforce (Mansour, 2014).
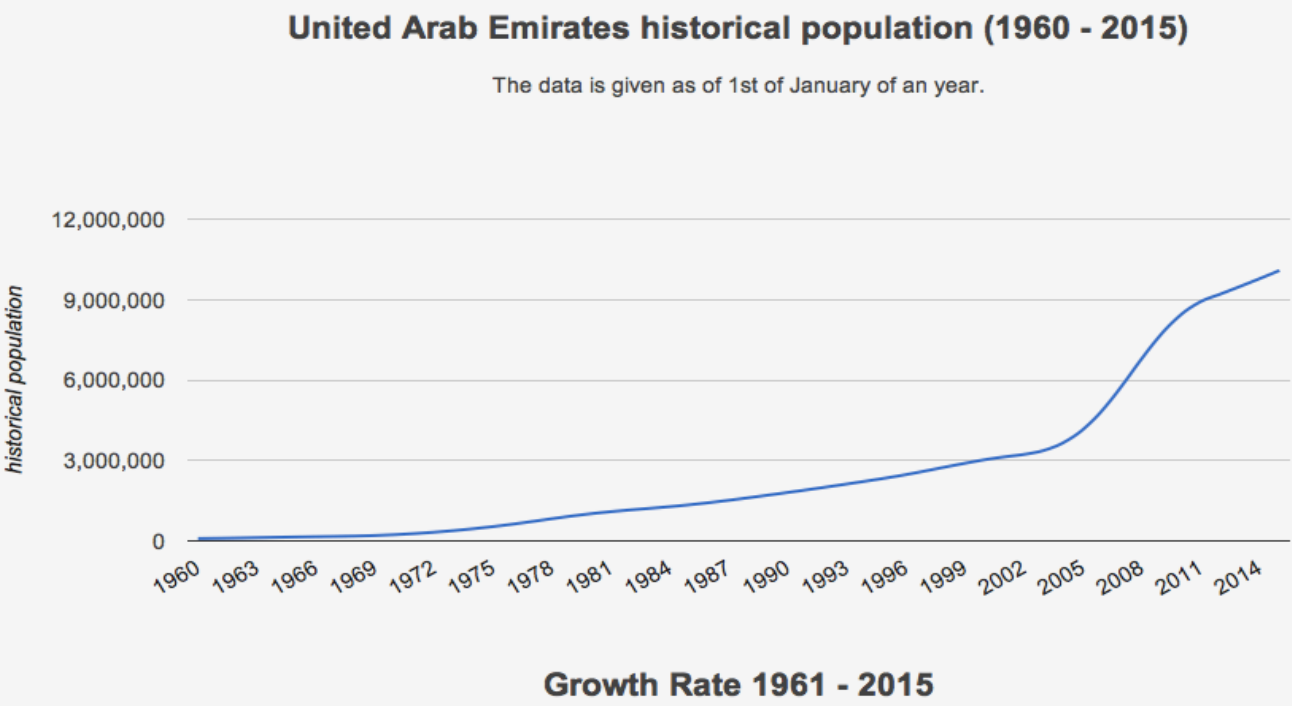

Figure (4): UAE Historical Population 1960 - 2015. Adopted from

\section{http://countrymeters.info/en/United_Arab_Emirates}

In this regard, and since 2008, the UAE authorities declared the year for National Identity. Demographic imbalance in the country crushed the nation's identity by increasing tendencies towards globalism and local interests of individual emirates at the expense of the federation (Al-Khouri, 2010). The Federal Demographic Council has actively promoted the 
notion of Emirates folklore, and established images of camels, horses, forts, coffee pots, dhows, and falcons have been actively used by the state to symbolize Emirati identity (al-Dhaheri, 2009) to remind the majority of who represents and dominates the society. In addition, the government launched a social development program called 'Watani', my nation, which aims at creating a discourse of National Identity that does not clash with multiculturalism in a diverse community where the essence of the Emirati identity can be maintained through inclusion rather than exclusion (Baharoon, 2012). In a whirl of 200 nationalities the people of the UAE face a risk of disappearing, however, some researchers suggest that the plural cultures contribute to the shaping of the multiple Emiratis Identities because of its openness that embraces political and cultural diversity.

\section{UAE Economy}

The modern UAE are so different from the Trucial States, out of which they grow (Hawley, 2007, p.9). On the opening day of The Government Summit 2015, Sheikh Mohammed, Crown Prince of Abu Dhabi and Deputy -Supreme Commander of the Armed Forces, addressed speech that reflects the current economic changes in the country and a future vision of UAE economy: "In 50 years, when we might have the last barrel of oil, the question is: when it is shipped abroad, will we be sad?" he asked. "If we are investing today in the right sectors, I can tell you we will celebrate at that moment" (The National, 2015).

According to the latest report of the UAE central bank the real GDP growth has reached to more than the expected 4.8 percent growth in 2014 from 3.5 percent in 2012-2013 on the back of stronger performance by the country's vibrant sectors: banking and finance, aviation, tourism and hospitality, trade and services manufacturing and real estate. Therefore, non-oil sectors now represent 69 percent of the UAE's GDP with oil accounting for the remaining third as the 
government continues its efforts to transform from an oil-based society to a knowledge-based society. A study by the Washington-based Institute for international Finance (IIF) indicates that the UAE's GDP is the second largest in the Arab world.

The Global Competiveness Report 2014-2015 issued by The World Economic Forum (WEF) name the United Arab Emirates the 12th most competitive nation globally in which the country advanced seven places in the overall competitiveness of its economy in one year, ahead of countries such as Canada, Denmark and South Korea (WAM, 2014). Furthermore, financial analysts predict that tourist influx in the region is set to grow over the coming 5-10 years with an estimate of 39.9 million international tourist arrivals by 2024 with a $\$ 28$ billion in tourist spending. This growth emerges as Dubai wins the bid to host Expo 2020 in 2013. Abu Dhabi is also investing in building its touristic destination, which includes the construction of the Louvre and the Guggenheim museums on Saadiyat Island.

\section{Towards Political Liberalization}

Commenting on the recent Arab Spring events in the Middle East and North Africa region and the prospects for political change in the UAE, al-Sayegh (2004) argues that the 9/11 attacks and the invasion of Iraq in 2003 are the main factors that raised concern worldwide about the lack of democracy in the Gulf, and she believes that diversification away from oil dependency will fuel success for democratization in the country. Similarly, Heard-Bey (2005) also points at 9/11 as the turning point that made the UAE tackle the democratic deficit with more urgency (p.367) in which she truly supports that changes will come about through consultation rather than confrontation (p. 375). In a more inclusive position, Koch (2011) believes in the idea that political reform was accelerated by external pressure to democratize, as well as the desire to put down Islamist movements both of which played an important role during 
the last decade. But Koch adds that local observation of reform measures implemented elsewhere in the region, a better education system and a freer media environment also contributed to the enhancement of political awareness among Emiratis (p.173).

Surprisingly, on the country's celebration of national day on December 2nd, 2005 His Highness Sheikh Khalifa bin Zayed Al Nahyan proclaimed, in his address to the nation, that elections would be implemented shortly to choose half the members of the (FNC), as part of the country's movement toward 'representative democratic regime' in its political system:

Considering the developments in our region, which is now witnessing transformation and reforms, the years ahead in our blessed march require a bigger role for the FNC by empowering it to be an authority that would provide great support and guidance for the executive arm of the government ... This would be done by ensuring a more participatory process and the entrenchment of "Shura" (consultations) policy" (The Emirates News Agency, 2005).

In addition to the aforementioned, the awareness-raising campaign launched by the Ministry of State for FNC Affairs in 2006 and 2011 explains how the nature of ruler-ship and power distance have changed over time. The campaign promotes consciousness on the aims of national elections, and develops a culture of political participations in the UAE. Finally, a key adaptive public leadership initiative led by His Highness Sheikh Mohammed Bin Rashid Al Maktoum, UAE Vice President, Prime Minister and Ruler of Dubai, is called The Government Summit marks the rapid political, economic and cultural changes in the country. It is an annual platform for dialogue and interaction focused on developing government services and policies not only for the UAE, but also as an international center for government innovation (Government Summit Report, 2013). Lately, the 2015 Government Summit was being held under the title 'Shaping Future Governments' with the presence of more than 97 countries from all over the world (The National, 2015). 


\section{The UAE - Cultural Values and Influences}

William Good's thesis (1963) is an ambitious study of changing family and kinship patterns in various Islamic countries. He asserts that dynamic economic and social forces are having profound influences on daily family life and these families are more likely to adopt a similar structure of the influences. He believes that social revolutions are occurring in different parts of the world as a result of war, mass media, changes in the work force, and labor force participation. These changes are mainly evident in the history of the Gulf and especially UAE who were heavily impacted by the British colonialism in the region. Discovery of oil in 1958 and its big revenues, rapid economic and infrastructure developments, and technological advances are having a great impact on the cultural identity of this largely traditional Muslim society .The younger generation has grown up in this traditional, yet Westernized society (Schvaneveldt, Kerpelman, \& Schvaneveldt, 2005), but their parents and ancestors are reared in a very different culture (Willemyns, 2008).

Religion and language. Jawad (1998) argues that there is great diversity among Middle Eastern countries, but Islam continues to serve as a unifying between these countries. In the UAE, Islam is the main religion, all UAE national are considered to be Muslims and sharia is the main source for legislation in the country. With the uprising religious ideologies in the region such as ISIS and Muslim Brotherhood, the UAE government started promoting a moderate version of Islam with a big control on religious activities. Unlike Saudi Arabia, the UAE constitution guarantees the freedom to exercise religious worship, and allows non-Muslims to openly practice their religion. UAE malls and outlets are well decorated for Islamic and nonIslamic celebrations and public holidays are granted for both Muslims and non-Muslims' 
celebrations. Even though UAE is projected as modern and fairly liberal state, it is still described as an Islamic state (el-Aswad, 2005).

Conservative Muslims and fundamentalists, commenting on gender roles, argue that women's liberation and education in any society will create immorality and instability in both the home and society through their exposure to Western thoughts and job markets. In the Middle East and the Gulf region in particular, social change has been very gradually in gender's roles because of some religious ideologies that restrict women's roles in a society. Nowadays, women are attending universities in a great numbers, and some are holding leadership positions such as minsters, ambassadors and CEOs due to modernization and economic developments in the region (Schvaneveldt, Kerpelman, \& Schvaneveldt, 2005).

Arabic is the official language of the country, but English is widely used in the business and in the private and public services including banking, health and education. Recently, Arabic has been eliminated as the language of instruction in schools and Federal universities in favor of the more universal English (Mills, 2008).

Globalization of higher education. UAE government leaders are highly aware now that oil will be gone in near future and that citizens have to be fully prepared to be active leaders of a diversified and flexible knowledge-based economy. UAE Vision 2021's, United in Knowledge indicator, emphasizes on the country's interest and commitment to secure high quality education to all Emirati citizens which reflects the country's current policies and strategic directions (UAE Vision 2021, 2015). In the early stages of nation's establishment, the assertion of Arab and Islamic identity was central to the young state and an aim for the UAE national higher education (Findlow, 2005). The country's early curricula valorized the Arabic language and the Islamic 
character of the state, which has abandoned the Egyptian-influenced education system (Shaw, 1997).

Currently, the UAE's large Western expatriates workforce as well as the economic and global forces have created a high demand for Western models of higher education downplaying the Egyptian-influenced earlier curricula since 1985 (Findlow, 2005; Shaw, 1997; Khalifah, 2010). Inkeles and Smith (1974) highlights the strength of the association between education and modernity suggesting that schools, and especially higher education, may be influential in encouraging greater modernity. It should be noted that, the number of Emirati students attending private schools has been gradually increasing over the last 10 years to over fifty percent across the country (al-Mulla, 2011).

Unlike the older generation, Emirati youth are educated in Western curricula delivered by Western educated-faculty mainly from the United States, United Kingdom, and Australia as in the case of UAE University, Zayed University and Higher Colleges of Technology. Khalifah (2010) carried a study at Zayed University to explore cultural changes in Emirati Muslim female university students as a result of their heavy exposure to Western thoughts, ideas, values and behaviors as they pursue their undergraduate education in a Western-modeled university in the United Arab Emirates. In his study, he found that the curriculum grounds students firmly in Western culture and thought in which Emirati Muslim female don't just talk in English, but they also act as Westerners. Accordingly, education system in the UAE mirrors the current tensions between the country's aspiration to modernity through the adoption of successful Western models, and the desire to preserve the Islamic and national identity, which are alarmingly changing the face of the country and the nation's cultural fabric. 
The age of social media. It has been argued that the mass media have long been linked to the historical development and emergence of national identities. However, the modern era of media globalization is playing a decisive role in creating transnational spaces of political discourse and mobilization (Nisbet \& Myers, 2010), which has a direct influence on the formation of cultural and political identity within these new information environments. UAE nation was firstly exposed to a radio station in 1966 followed by Abu Dhabi Television in 1969. Then in 1972 Dubai established its first English channel and lastly Sharjah Television in 1989. Since the early 1990s the UAE broadcasters went international on satellite (Ayish, 2013) and news and information started pouring into the homes of Emiratis in the form of movies, documentaries, fashion, healthcare, $\mathrm{CNN}$ and Fox news (Schvaneveldt, Kerpelman, \& Schvaneveldt, 2005).

Hollywood movies can be seen in all of the movie theaters across the country and the youth are the most interested Western movies and music, social media and fashion. Notably, most of young people in the country speak and communicate fluently in English and are fully engaged in inviting newness from the West and to also appreciate the Islamic values and traditions of the society (Schvaneveldt, Kerpelman, \& Schvaneveldt, 2005). According to the Arab Social Media Report 2014 (ASMR) data, Qatar now leads in the Arab region, followed by the UAE, with Jordan, Lebanon, and Bahrain rounding out the top five countries in terms of Facebook penetration, and has the third highest Twitter penetration rate (4\%) after Egypt and Saudi Arabia (Arab Social Media Report, 2014). In this regard, Murphy has noted that Arab use of ICTs and the emergent Arab public sphere are having a big influence in creating multiple identities among Arab populations which collide or integrate with more global identities, and are reconfiguring Arab notions of self and otherness (Murphy, 2009). Social media is still in its 
infancy in the Arab world, but it played a significant role in enabling rapid formation of networks and sparking the events of Arab Spring across MENA region.

Intergenerational differences - Women. In Emirati Women: Generations of Change, Jane Bristol-Rhys captures the life of women in extended households in the city of Abu Dhabi. She draws an image of three generation of Emirati women living in the same household. First, the grandmothers who were raised and who raised their children in the pre-oil period. These 'thin wiry' grandmothers kept heard of goats and cows on the large family compound and carried different activities: taking care of kids, cleaning, cooking, collecting wood and making fresh butter for the family. Second, the middle-aged women who were children in the 1960s and 1970s, when the conditions were shifting and are the first generation to move into big places with imported servants and nannies to take care of basic household needs and look after children. Finally, their daughters are the current university students who are born and raised in wealth. She describes the third generation as a modern generation with fluency in foreign languages, and an obsession with the Western music and the latest fashion trends in Europe (Bristol-Rhys, 2010; Rugh, 2007).

Schvaneveldt, Kerpelman, and Schvaneveldt (2005) conducted a study at Zayed University to explore generational relationships between matched pairs of mothers and daughters in the UAE in the context of rapid cultural and economic transformation. The study suggests that some of the changes are occurring in generational beliefs and attitudes toward marriage, family life, childcare practices, gender role attitudes, and fertility. In the study, daughters reported a desire to delay the age of marriage, and to have a professional career in the future, and mothers were more likely to value and favor the older culture of the UAE, which is no longer exist in life of Emirati family nowadays. 


\section{Purpose of The Study}

The UAE, like many other countries in the region has witnessed tremendous changes over the past 15 years. It is a young country with a young population and many political, social, and cultural changes as presented in the previous section. There has not been much research about the cultural values of the UAE in generational perspectives, and there has been rapid change. Multinational foreign presence, educational policy, advances in communication and transportation technologies, and economic activities are leading to much faster diffusion of ideas and cultural values of the younger generation in the nation. Every foreigner comes from a nation. The nation is not just defined by borders on the map, but it is a set of beliefs that travel with a person and can survive and have influence on the national identity of a minority.

This research study explores the changes in cultural values among two generations in this region. The data will not only show generational differences or similarities, but also generational struggles to adopt in this traditional, yet largely Westernized society. The implications and utility from this study are profound in terms of understanding the dynamic societal and value changes, and tensions that come to society as a result of the rapid cultural and economic changes.

The data will capture the aspirations and desires of younger generations and future leaders of the country who will socialize a new generation in the UAE. These younger generations are the change agents for social revolution in this oil rich nation. These data are crucial in helping the government, older generations and the younger one in the UAE to fully understand the gap between various generations in terms of their present and future goals. Finally, this study will provide significant insights to the field of cross-cultural communication in business and cultural contexts. 
It is hypothesized that the younger generation of the UAE will differ from the older generation on Hofstede's five dimensions, and both generations' index scores will register differently than the original IBM scores that were registered in the years of country's establishment 40 years ago. In this chapter, the author predicts how the younger generation might score differently than the older one on the five dimensions.

\section{Hypotheses}

Power distance. The United Arab Emirates scores 90 on power distance which is high compare to the world average in this dimension, according to Hofstede's studies. However, recent trends in the region suggest that UAE younger generations are more likely to report preferences for participative and consultative leadership styles than the older generations who keep self-disinterested in showing disagreement and place greater value on autocratic leaders. This change has occurred dramatically in the political arena where there have been "pressure from globalization and political fallout from events such as the 9/11, the Iraq War (Koch, 2011, p.173) and more recently Arab Spring. Also, the awareness-raising campaign in 2006 and 2011 by the Ministry of State for FNC Affairs developed a culture of political participation in the UAE. These displays of power of change and willingness to participate and be engaged suggest that younger generation is becoming less tolerant of power distance compare to the older generation. Based on our arguments we propose that these value score will have shifted, and that because of regional socio-political events and the Western influence, younger generations will exhibit lower power distance than the older generations.

Hypothesis 1: The cultural values of youth are more likely to be associated with low power distance than that of the older generations. 
Individualism. The United Arab Emirates lies toward the collectivist end of the individualism dimension with a score of 25 . UAE culture is still viewed as a group-oriented that imposes a psychological distance between in-group and out-group members. In-group members are expected a strong loyalty and a sense of pride to be Emiratis. Khelifa (2010) suggests that Emiratis are still part of the traditional Arab culture that values altruism, helping others, honesty, forgiveness, and elderly respect over independence. This tendency toward collectivism and altruism is putting the welfare of others before one's own no matter how smaller or bigger is the family unit. He further claims that young Emiratis are at the same time high on individuality, independence and autonomy, which indicates an increased appreciation for the Western thought patterns, and underpinning philosophy of individualism and independence (El Walily \& Al Amri, 2005). Therefore, Arab Muslim Emiratis are not expected to be individualistic because attributes such as birth and ethnicity are basis for social standing and privileges form social philosophies that defer to the interests of the larger group.

Hypothesis 2:The cultural values of both generations in the UAE are more likely to be associated with Collectivism

Masculinity. According to Hofstede's studies, UAE scores 50 on this dimension and can be considered to be neither masculine nor feminine, but this too is changing. With the UAE rapid economic changes and the transformation toward a diversified knowledge-based economy emphasizes the importance of competition and achievements. The UAE government and the role model of younger generations H.H. Shiekh Mohammed Bin Rashid AlMaktoum, UAE Vice President, The Prime Minster and Ruler of Dubai stress on competition and educate younger generations to be "number one" in everything and achieve the "biggest and highest." Recent initiatives and awards in the country suggest that the UAE younger generations are more likely 
to be masculine, whereas the older generations are more likely to be feminine. The younger generations are more likely to be driven by competition, innovation and success by being the best in the field, while the older generations are more likely to maintain good working relationship with supervisor and live in areas where family live.

Hypothesis 3: The cultural values of youth are more likely to be associated with masculinity than that of the older generations.

Uncertainty avoidance. UAE tends to have high preferences for avoiding uncertainty but the current and future knowledge-based economy may be affecting generational tolerance for uncertainty. One possible factor of this change is the country's rapid economic growth that encourages entrepreneurial activities and innovation. Last October, H.H. Shiekh Mohammed Bin Rashid AlMaktoum lunched strategies to be the most innovative nations in the world within seven years. He quoted saying "the UAE is already the most innovative Arab nation. Our target is to be among the most innovative nations in the world. The competitiveness race demands a constant flow of new ideas, as well as innovative leadership using different methods and tools to direct the change." This will effectively increase generational willingness to be more tolerant of new ideas and opinions. UAE younger generations are more likely to tolerate uncertainty while the older generations are more likely to feel threatened by ambiguity and living in the unknown. Hypothesis 4: The cultural values of youth are more likely to be associated with low uncertainty avoidance than that of the older generations.

Long-term orientation. Hofstede (2001) identifies a dominant correlation of LTO with economic growth and the top five countries are known for their fast economic growth. It is notable that the UAE has gone to great lengths to flourish and diversify its economy in order to be become a strong competitor in the international markets. The rapid economic growth over the 
past decades urges the economy to modernize, and transition from an oil-based to a knowledgebased society for a future sustainability. This shift is manifested in future-oriented visions: UAE vision 2021 and Abu Dhabi vision 2030. More recently, UAE government's future projects have increased in scope and size, which set an example of future oriented government. Unlike the government, Emiratis are not yet future oriented (Benesh, 1996, p.161). Hofstede (2001) explains that Muslim societies are more likely to score low on LTO because many of the Muslim people are still caught in a definition of truth that hinders coping with modernity (p.369).

Hypothesis 5:The cultural values of both generations in the UAE are more likely to be associated with Short-term Orientation 


\section{CHAPTER THREE \\ METHODLOGY AND RESULTS}

\section{Participants}

UAE University was selected as the site for the research for the following reasons, and as Teaching Assistant at the department of Political Science, it is considered more attainable and relevant to limit the implementation of Hofstede's VSM (08) to United Arab Emirates University in AlAin, and is identified key informants for the current study for several reasons:

- It is the first and the oldest of three main federal universities in the nation, which was established in 1976 and is largely Westernized.

- It has the largest ratio of Emirati students around 14,024: 10,000 are Female undergraduate students and 3000 are the Males students (UAEU Fact Sheet, 2015).

- It has more than 644 faculty members whom are mostly Western from the US, UK, Australia and Emirati nationals who relieved their doctoral degrees from US and UK higher education institutions since 1980s.

- It provides access to the second and third generations of the country who earned their degree from the university or still doing their degrees in a Westernized institution.

- It has the first departments of Political Science, Philosophy, Leadership and Entrepreneurship in the country.

- All National Professors are educated in the West, and are the ones who have published controversial articles in Emirati newspapers during the Arab Springs and the current events in the Middle East, in which they advocate for political reform in the system in a very open ways. 
- It is representative in nature because students, administrators and faculty come from the seven Emirates of the country.

Hofstede and Minkov (2010) recommend an ideal size for any country to be researched should be more than fifty for each population sample. The sample in this study far exceeds the criteria in both samples. The samples for this study were selected based on Frey's (1970) two criteria of accessibility and representativeness. The author decided to survey 100 female and male-undergraduate students, and 70 faculty and administrators within the UAEU institution for more of a representative sample that represents national people of the country.

One hundred and forty nine questionnaires completed survey were returned. A total sample of 93 represents undergraduate students and 56 represents faculty and administration units. Twelve surveys were excluded from the undergraduate sample and three from the second population sample because they are from different nationalities and the rest are incomplete. The achieved valid sample is 133 respondents, which represents 81 of the undergraduate sample and 52 of the faculty and administration sample. All of the valid responses are considered appropriate and representatives because the sample size is still more than 50 .

\section{Demographic Characteristics of the Participants}

The following tables and figures illustrate the sample distribution according to gender, age, Emirates, job title or administration unit and students' major.

Table (2)

Sample Distribution According to Gender

\begin{tabular}{clrr}
\hline Category & Gender & Frequencies & \multicolumn{2}{c}{ Percentage } \\
\hline Undergraduate Students & Males & 17 & 21 \\
& Females & 64 & 79 \\
& Total & $\mathbf{8 1}$ & $\mathbf{1 0 0}$
\end{tabular}




$\begin{array}{clrr}\text { Faculty/Administrations } & \text { Males } & 12 & 23 \\ & \text { Females } & 40 & 77 \\ & \text { Total } & \mathbf{5 2} & \mathbf{1 0 0} \\ \text { Total Sample } & \text { Males } & 29 & 22 \\ & \text { Females } & 104 & 78 \\ & \text { Total } & \mathbf{1 3 3} & \mathbf{1 0 0}\end{array}$

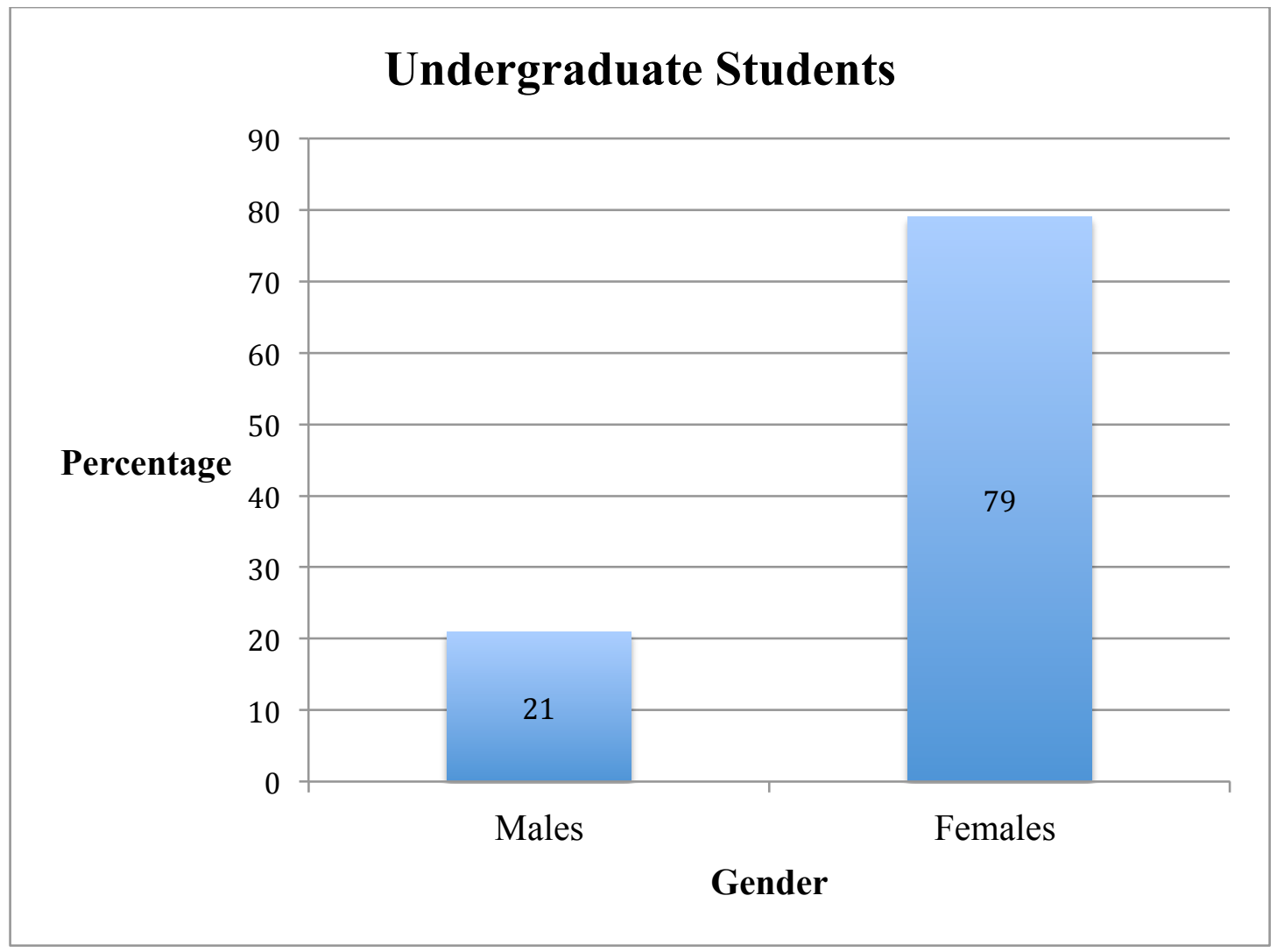

Figure (5): Sample Distribution According to Gender 


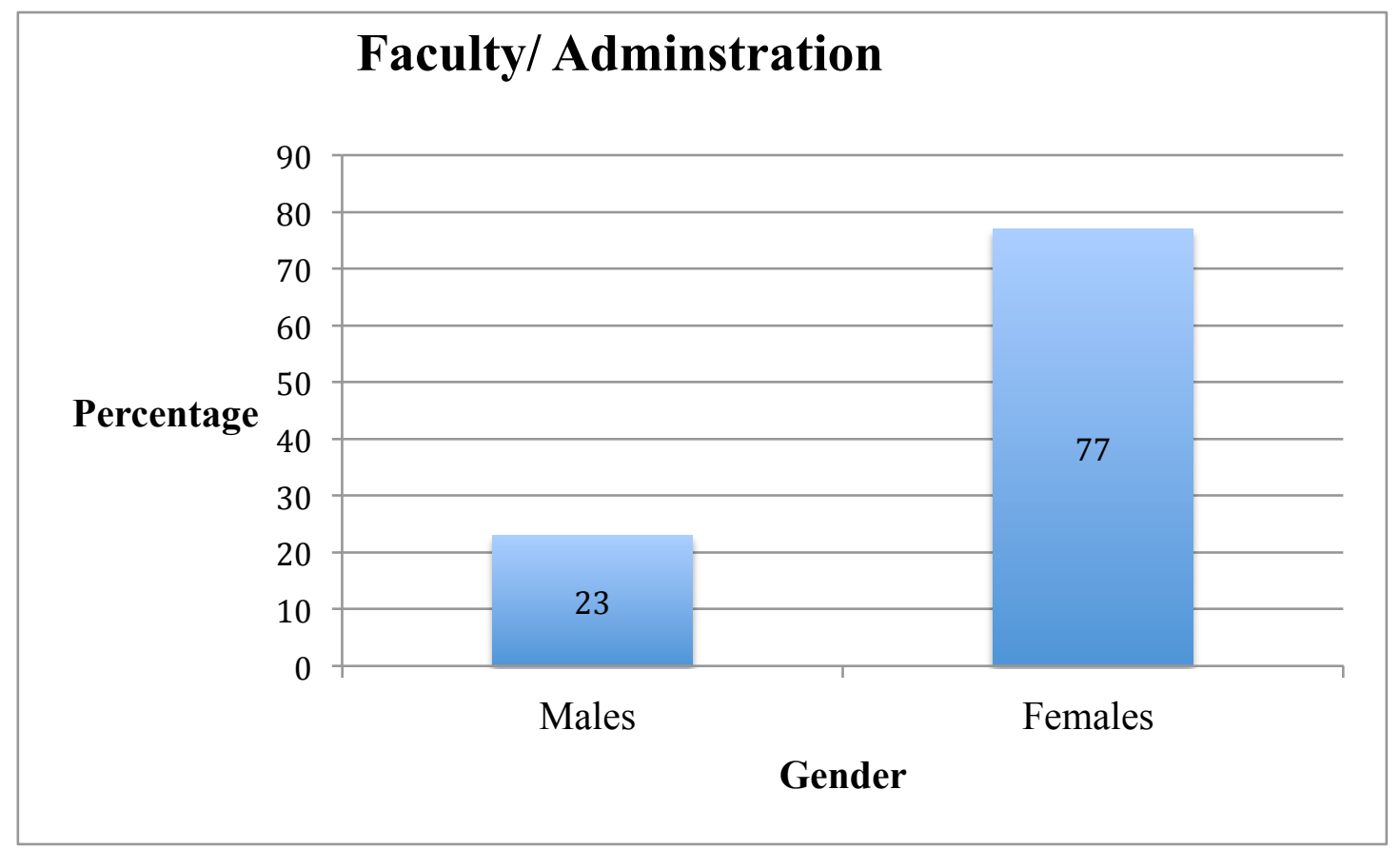

Figure (5): Sample Distribution According to Gender

\section{Table (3)}

Sample Distribution According to Age

\begin{tabular}{lcc}
\hline Age & Frequency & Percentage \\
\hline Under 20 & 13 & 10 \\
$20-24$ & 69 & 52 \\
$25-29$ & 8 & 6 \\
$30-34$ & 18 & 14 \\
$35-39$ & 12 & 8.5 \\
$40-49$ & 9 & 6.5
\end{tabular}


$50-59$

60 and Above

Total
4

0

133

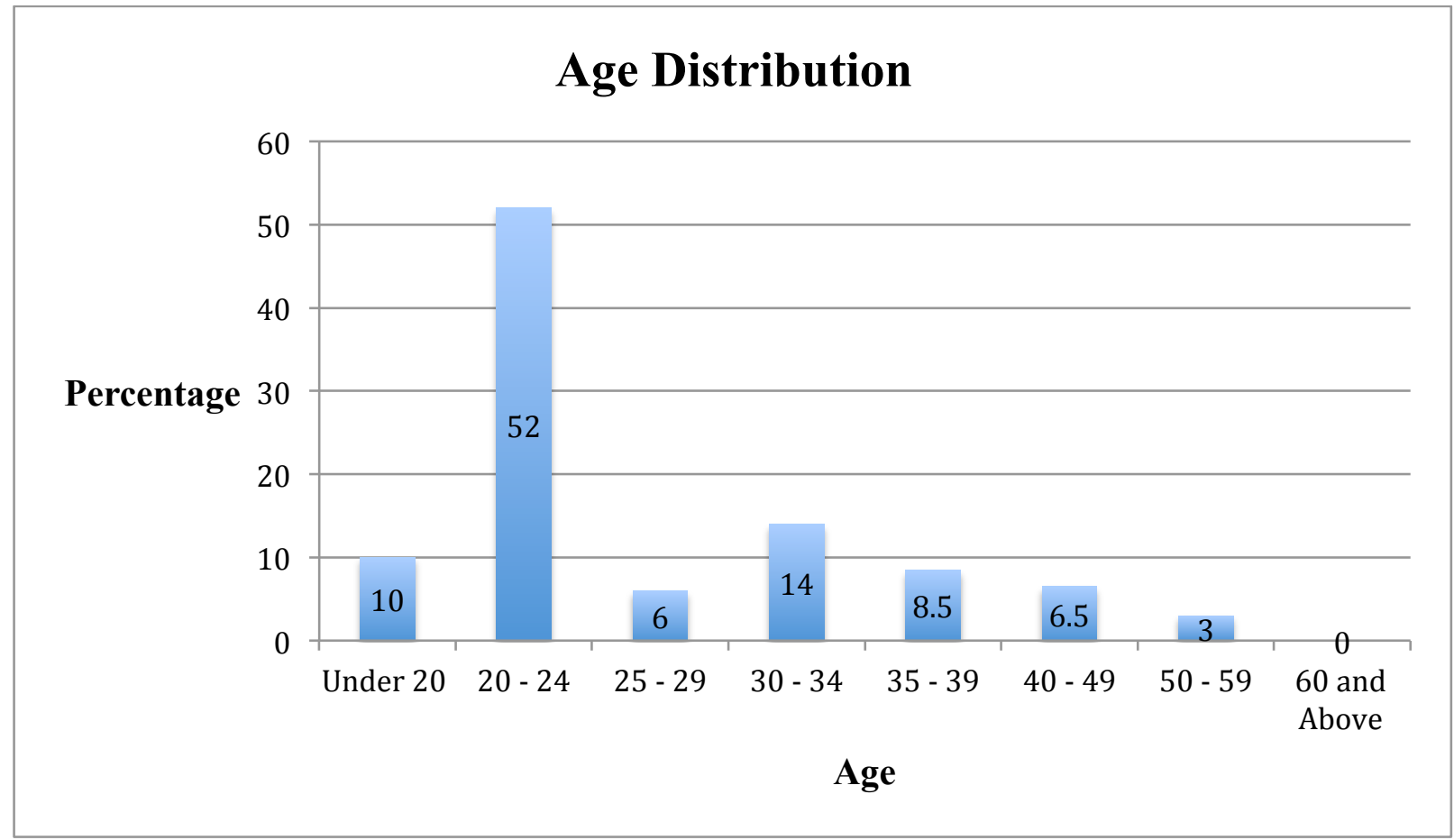

Figure (6): Sample Distribution According to Age

Table (4): Sample Distribution According to Emirates

\section{Emirate}

\section{Frequency}

\section{Percentage}

Abu Dhabi

86

65

Dubai

12

9

Sharjah

11

8

Ajman

3

2 
$\begin{array}{lll}\text { Ras AlKhuima } & 11 & 8\end{array}$

$\begin{array}{lll}\text { Fujairah } & 10 & 8\end{array}$

Umm Al Quwain $\quad 0 \quad 0$

$\begin{array}{lll}\text { Total } & 133 & 100\end{array}$

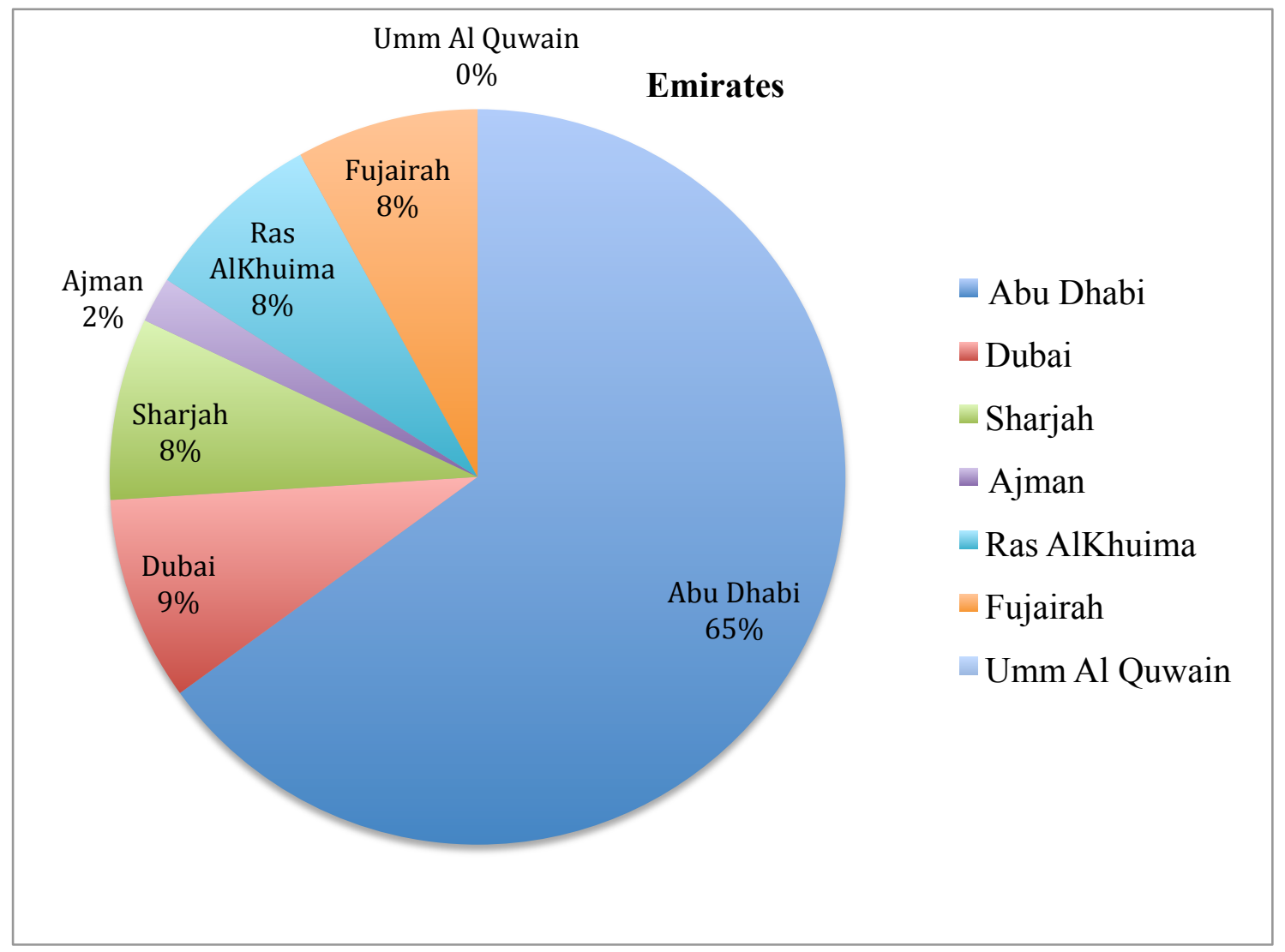

Figure (7): Sample Distribution According to Emirates 
Table (5)

Sample Distribution According to Job Type

\begin{tabular}{lll}
\hline \multicolumn{1}{c}{ Job Type } & Frequency & Percentage \\
\hline Full-Time Student & 81 & 61 \\
Semi-Skilled Manual Worker & 1 & 1 \\
Secretary & 16 & 2 \\
Vocationally trained craftsperson, & 3 & \\
technician, IT-specialist, nurse, & 12 & 9 \\
artist & 15 & 11 \\
Academically trained professional & 133 & \\
or equivalent & & 4 \\
Manager of one or more & & \\
subordinates & 5 & 100 \\
Manager of one or more & & \\
managers & & \\
\hline Total & & \\
\hline
\end{tabular}




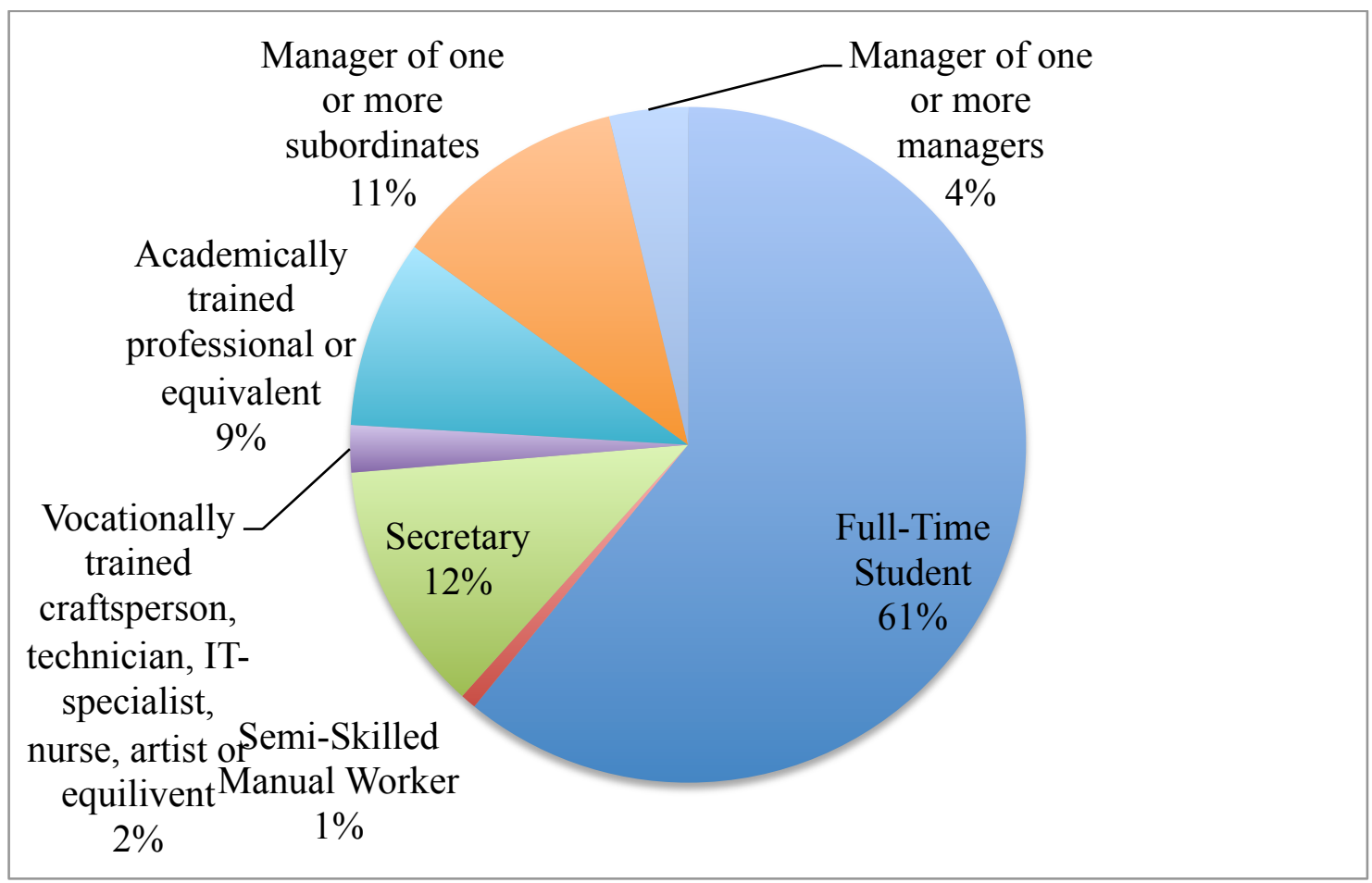

Figure (8): Sample Distribution According to Job Type

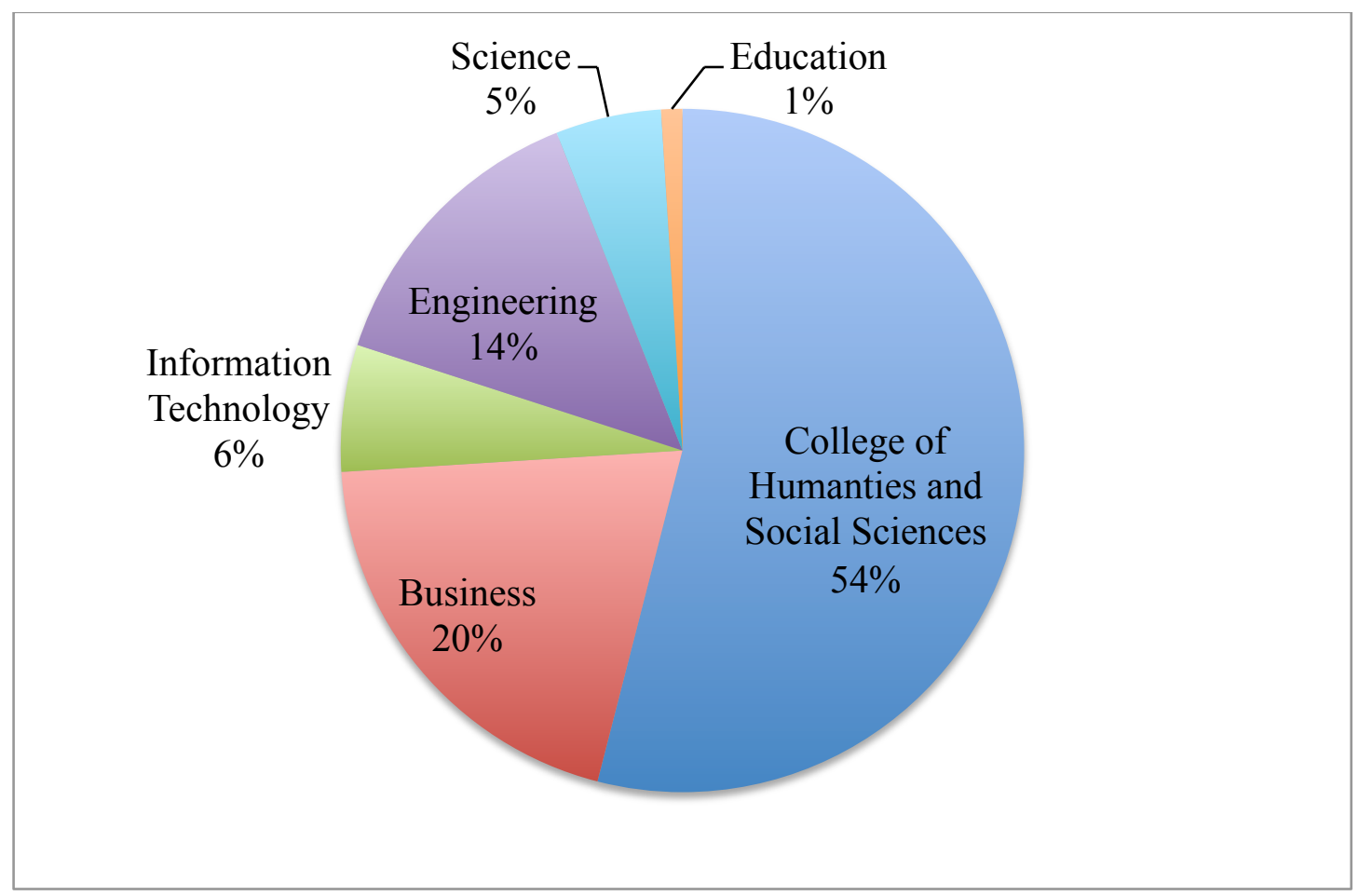

Figure (9): Sample Distribution According to Students' Colleges 


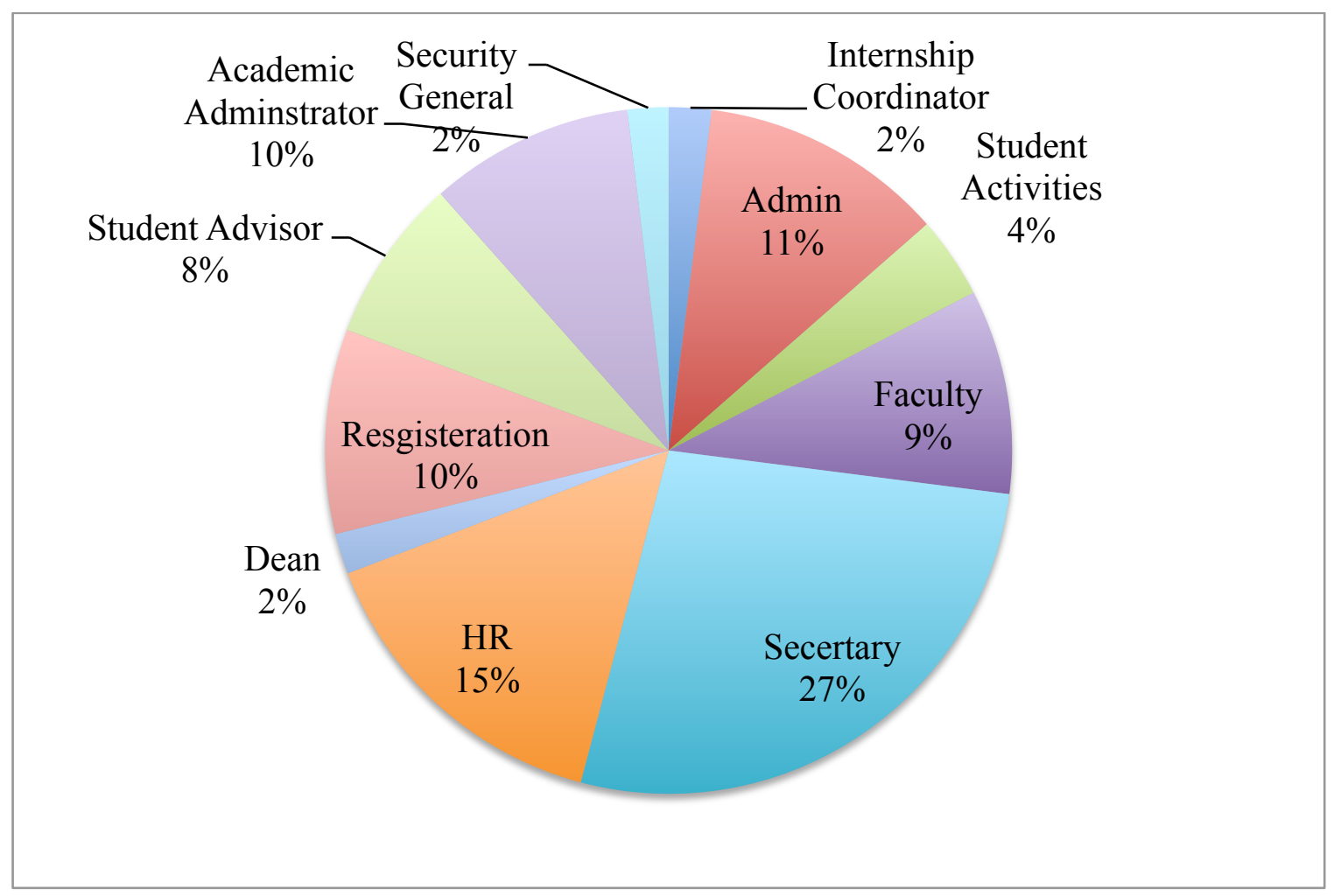

Figure (10): Sample Distribution According to Faculty and Administration's

Departments

\section{The Research Instrument}

The instrument used in this research was Hofstede’s Value Survey Model 2008 (VSM08). It is a 37-item paper and pencil questionnaire developed by Hofstede for comparing leadership cultural values of the older and younger generations. Respondents indicate their answers using a five point Likert-type scale. The VSM 08 measures seven dimensions of culture on the basis of four questions per dimension. The researcher chose only five dimensions to assess including: power distance, individualism- collectivism, masculinity-femininity, uncertainty avoidance and long-term orientation. The score of each dimension is calculated using a formula derived by Hofstede so that results will approximate between 0-100. The VSM 08 is available in different languages including Arabic and English versions. The Arabic version of the VSM 08 
was distributed to all study participants (the English version is attached in Appendix A). Additionally, the survey included nine questions focused on the demographic profile of respondents (see Appendix A).

\section{Procedure}

UAE University Vice Chancellor and National Teaching Assistants Office at UAEU were very helpful in explaining the steps that should be followed to get the authorization from the university to access the intended sample and distribute the surveys. First, an application of Institutional Review Board along with the questionnaire, informed consent, a letter of approval from University of San Diego, and the detailed research proposal had to be submitted to the UAEU Ethical Committee of College of Humanities and Social Sciences (sample of the IRB Approval is in Appendix B).

In January $11^{\text {th }} 2015$, access was granted by Social Sciences Ethical Committee at UAEU to distribute the survey to the population sample. The researcher contacted the College of Humanities and Social Sciences via email to describe the purpose of the survey and to have access to three General Education structured courses within the college. In February 2015, the author flew to UAEU to self-administer the survey distributions process.

The survey was administered to two general education courses in the female side of the university and one in the male side: Political Thought and Emirates Society courses, and Europe and the United States course in the male side. Local students were voluntary invited to participate in the study after agreeing to the informed contest of the study. The undergraduate students completed the survey in classroom settings within a period of 20 to 35 minutes. The researcher was present during the defined period to answer or explain components of the research. 
In the case of faculty and administration units, the researcher visited all units and departments within the UAEU, and clearly defined and explained the purpose and the outcome of the research. The door left open for any interested respondent to participate in the study randomly within the following specified criteria: Emirati nationals who are from third, fourth, and fifth generations. The respondents were allowed to keep the questionnaires for four days and the researcher picked them from each unit on Thursday, February $12^{\text {th }} 2015$.

The researcher distributed the questionnaires by hand to every participant in the study and read the instructions clearly of how a respondent can approach the questionnaire.

\section{Analysis and Results}

Hofstede's study of cultural values is replicated for use in this study examining dynamic societal and value changes of the older and younger generations of the UAE. For this study, a well-known validated instrument of Hofstede (VSM08) questionnaire is conducted to indicate how the younger and older generations of the UAE indices differently on power distance, uncertainty avoidance and masculinity dimensions, and similarly on individualism and long-term orientation dimensions. The author also utilizes the data to survey how the UAE scores on the five dimensions compare to Hofstede's old data of IBM.

In order to test the hypotheses, the study relied on a statistical analysis using the t- test, distributions of frequency and Hofstede's index formula as per VSM08 for evaluating each of the five dimensions. Excel and StatPlus (2013) are utilized to compute the automated results.

\section{Descriptive Statistics of the Five Dimensions' Indices}

Question Items of each dimension. All content questions are scored on five-point scales $(1,2,3,4,5)$ from of utmost importance to of very little or no importance. Index scores are derived from the mean scores on the questions of Hofstede's VSM08 for each dimension. Table 
(6) shows question items that make up each dimension with the registered mean scores of each item for both the younger and older generations of the UAE.

Table (6): The Mean for each of the Cultural Dimensions Power Distance (PDI) Index

\begin{tabular}{lcc}
\hline \multicolumn{1}{c}{ Question Items } & Younger Generation $\overline{\mathrm{x}}$ & Older Generation $\overline{\mathrm{x}}$ \\
\hline $\begin{array}{l}\text { Q2. Have a boss (direct } \\
\text { superior) you can } \\
\text { respect }\end{array}$ & 1.46 & 1.53 \\
\\
$\begin{array}{l}\text { Q7. Be consulted by your } \\
\text { boss in decisions } \\
\text { involving your work }\end{array}$ \\
$\begin{array}{l}\text { Q23.Are subordinates } \\
\text { afraid to contradict } \\
\text { their boss }\end{array}$ \\
$\begin{array}{l}\text { Q.26 An organization } \\
\text { structure in which certain } \\
\text { subordinates have two } \\
\text { bosses should be avoided } \\
\text { at all cost }\end{array}$
\end{tabular}

\section{Individualism (IDV) Index}

Q1. Have sufficient time for your personal or home life 
Q6. Do work that is

interesting

Q.9 Have a job respected by

1.91

1.78

your family and friends

\begin{tabular}{lcc}
\hline Masculinity (MAS) Index & & \\
\hline $\begin{array}{l}\text { Q3. Get recognition for } \\
\text { good performance }\end{array}$ & 1.44 & 1.65 \\
$\begin{array}{l}\text { Q5. Have pleasant people to } \\
\text { work with }\end{array}$ & 1.38 & 1.63 \\
$\quad$ Q8. Live in a desirable & 1.91 & 1.96 \\
$\quad$ area & 1.34 & 1.61 \\
$\begin{array}{l}\text { Q10. Have chances for } \\
\text { promotion }\end{array}$
\end{tabular}

\section{Uncertainty Avoidance (UAI) Index}

Q16. How often do you

2.65

2.75

feel nervous or tense

Q20. All in all, how would

1.79

1.88

you describe your state of

health these days

Q24. One can be a good

manager without having a

precise answer to every

question that a subordinate

may raise about his or her

work

Q27. A company's or

organization's rules should not be broken-not even 
when the employee thinks

breaking the rule would be

in the organization's best

interest

Long-Term Orientation (LTO) Index

Q15. If there is something expensive you really want to buy but you do not have enough money, what do you do?

Q18. Are you the same home

Q25. Persistent efforts are

$1.28+1.48$

Q28. We should honour our heroes from the past

\section{Summary of Indices Result}

Using the results of the mean analysis for the answers of Hofstede's VSM08 questions, index scores of the older and younger generations are calculated. The formulas and calculations are the ones designed and used in Hofstede's VSM08 (2008), which is exhibited in Appendix (C). Results of the dimensions' index calculations (Index scores and standard deviations) for the independent variables of the five dimensions are shown in Table (7) to explore statistical differences between the younger and older generations. 
Table (7): Comparison of Generations on Cultural Dimensions

\begin{tabular}{lcc}
\hline \multicolumn{1}{c}{ Index } & $\begin{array}{c}\text { Younger Generation } \\
\text { Index (SD) }\end{array}$ & $\begin{array}{c}\text { Older Generation } \\
\text { Index (SD) }\end{array}$ \\
\hline Power Distance Index & $43.67(1.18)$ & $47.5(1.14)$ \\
Individualism Index & $18.57(0.87)$ & $18.17(0.86)$ \\
Masculinity Index & $17.85(0.77)$ & $12.78(0.86)$ \\
$\begin{array}{l}\text { Uncertainly Avoidance } \\
\text { Index } \\
\text { Long-Term Orientation }\end{array}$ & $19.18(1.1)$ & $27.59(1.13)$ \\
& $28.06(0.98)$ & $25.76(0.99)$ \\
\hline
\end{tabular}

\section{Results of the $t$-test Analysis}

The $t$-test analysis is conducted to test the proposed hypothesis in order to determine if any significant differences exist between the younger generation and the older one in responding to the questions of each of the five dimensions.

The results in Table (8) suggest that there are no significant differences at $\mathrm{P}$-value $<.05$, between the younger and older generations' tolerance to unequal distribution of power (power distance), fear of the unknown (uncertainty avoidance) and quality of life and gender roles in a society (masculinity). Based on this statistical analysis, H1, H3, H4, which state that the younger generation of the UAE scores lower on power distance, masculinity and uncertainty avoidance than the older generation are not supported in favor of the null hypothesis.

The results of individualism and long-term orientation dimensions in Table () confirms $\mathrm{H} 2$ and $\mathrm{H} 5$ as predicted by the author, which state that there are no significant differences 
between the younger and older generations of the UAE regarding the tight knit social framework and the exhibition of short-term orientation. Based on this statistical analysis, $\mathrm{H} 2$ and $\mathrm{H} 5$ are supported.

Table (8): T-Test Results

\begin{tabular}{lcccccc}
\hline Index & $\begin{array}{c}\text { Younger } \\
\text { Generation }\end{array}$ & $\begin{array}{c}\text { Older } \\
\text { Generation }\end{array}$ & T-Value & P-Value & $\begin{array}{c}\text { Degree of } \\
\text { Freedom }\end{array}$ & Alpha \\
\hline PDI & 43.67 & 47.5 & -0.1688 & 0.435675 & 6 & \\
IDV & 18.57 & 18.17 & 1.3474 & 0.1132 & 6 & \\
MAS & 17.85 & 12.78 & 1.2041 & 0.136946 & 6 & 0.05 \\
& & & & & & \\
UAI & 19.18 & 27.59 & -0.0225 & 0.491386 & 6 & \\
LTO & & & & & &
\end{tabular}

\section{UAE Indices Scores Compared to Hofstede's (1980) Original Data}

Surprisingly, UAE society scores significantly different from the original data of Hofstede that was collected 30 years ago during the first years of the country's formation as a federal state. The UAE society, as presented by the study sample in Table (9) scores low on power distance, masculinity and uncertainty avoidance, which suggest that the Emiratis now have low tolerance to unequal distribution of power, do not feel widely threatened by ambiguous 
events, and are feminine society in terms of quality of life. The current cultural profile of the country contradicts with Hofstede's scores of each dimension.

Table (9): Study Results Compared to Hofstede's Findings

\begin{tabular}{lcc}
\hline Index & UAE Society & Hofstede (1980) \\
\hline Power Distance Index & 23.57 & 90 \\
Individualism Index & 18.42 & 25 \\
Masculinity Index & 16.57 & 50 \\
Uncertainty Avoidance Index & 23.04 & 80 \\
& & N/A \\
Long-Term Orientation & 30.3 & \\
\hline
\end{tabular}




\section{CHAPTER FOUR}

\section{DISCUSSION, LIMITATION AND FUTURE DIRECTION}

This section focuses on a discussion of the results in relation to the proposed hypothesis and research outcomes. The discussion sheds the light on the registered scores of the younger and older generations of the UAE on the five dimensions, and explains the distinctive characteristics of UAE society that account for any deviation from the predicted hypothesis as indicated by the author.

\section{Emirati Power Distance Index (PDI)}

The younger and older generations of the UAE, as represented by the study sample score small-medium on power distance. Younger generation scores 43.67 and the older generation scores 47.5 , which suggests that both generations are becoming less tolerant to unequal distribution of power and resources. This contradicts the predicted difference between the two generations, and suggests that both generations are more likely to exhibit lower power distance. The author predicated a statistical difference and a change on power distance value between two generations based on recent regional socio-political events and several predicators. The author highly stressed on social stratifications and tribal system that mistakenly expected to cause a significant difference between the two generations.

UAE is a wealthy state that started offering a unique welfare system where basic needs including high-quality health care and education, social security, family allowances, subsided electricity and water, free housing and no tax charge are attended by the UAE government and royal patronage. Wealth distributions in the UAE can be interpreted as a consequence for a 
smaller power distance particularly among the people of the UAE capital, Abu Dhabi, in which they represent 65 percent of the total respondents from the seven emirates. Hofstede (2001) suggests that wealth correlates negatively with power distance, which might result in a middle class society that lessens the gap between the powerful and powerless members of the society (p.216). In addition, given the nature of the surveyed sample and the cultural profile of UAE University's Western influence, all participants are college-educated who are alumni or current students of the largely influenced environment. Hence, it is concluded that wealth is an influential effectors on power distance index and the surveyed sample at UAE University are subject to Western influence because teaching and higher education model is largely based on North American's publications and paradigms.

\section{Emirati Individualism Index}

The younger and older generations of the UAE, as represented by the study sample score low on individualism. Younger generation scores 18.57 and the older generation scores 18.17, which suggests that both generations lie toward the collectivist end of the individualism dimension. This confirms the predicated value of UAE society, which is characterized by collectivism.

The author believes that UAE culture is a group-oriented society that places greater value on altruism, helping others, honesty, forgiveness, and elderly respect over independence. As indicated in previous sections, Emirati people in particular have the tendency to put the welfare of others before one's own no matter the distance or the size of the houses or families. Traditionally, families were a single, large, extended economic unit. Nowadays, Emiratis live in nuclear families, separate houses, women go out to work, but both the younger and older generations have not out grow the close ties of the extended families. Therefore, the author 
presumes that the strong presence of social attributes such as birth, ethnicity and nationalism suggest that collectivist practices are still present in the values and behaviors of the young Emiratis who at the same time place increase appreciation for the Western patterns of life.

Moreover, Hofstede (1997) suggests a strong relationship between Individualism and national wealth in which he believes that individualism-collectivism differences will survive for a long time, and yet if there is to be any shift on causality between national cultures, it should be towards individualism. The author totally agree with Hofstede that the deep root of UAE national culture makes collectivist practices survive in the context of rapid economic and cultural development in the nation.

\section{Emirati Masculinity Index}

The younger and older generations of the UAE, as represented by the study sample score low on masculinity. Younger generation scores 17.85 and the older generation scores 12.78, which suggests that both generations are strongly feminine in which both males and females are supposed to be modest and caring for others; and quality of life is a sign of success. The score of the younger generation on masculinity is significantly lower than expected by the author.Analyzing the competitive business environment in the UAE and the greater emphasis on the importance of competition and achievements by H.H. Shiekh Mohammed Bin Rashid AlMaktoum, UAE Vice President, The Prime Minster and Ruler of Dubai, the author arrives to conclusion that UAE youth are driven by competition, innovation and success, which characterizes masculine generation.

The author believes that low masculinity score is represented by the total undergraduate female participants in the study, which accounts for 64 participants out of 81 participants, and is represented by 79 percent of the younger generation participants in the whole study. Another 
factor would be associated with the percentage of participants from college of humanities and social sciences, which means that the dominant societal values are caring for others and improving life. College of humanities and social science participants represent 54 percent of total surveyed sample.

Although the younger generation scores low on masculinity, the author believes that Emirati society still exhibits some characteristics of high masculinity based on daily life observation of social masculine behavior in the UAE. The author argues that the low score is quite unrealistic due to several factors. Islamic teachings and social tradition of the country play a significant factor in shaping the roles of men and women in the society. Accordingly, men should lead and be assertive, but women need to be feminine and tender. Some of high masculinity characteristics are listed as follows (Hofstede, 2001, p.228):

- $\quad$ Men should be assertive, tough, ambitious, and take care of performance.

- $\quad$ Money, advancement, promotion, and high wages are highly important.

- $\quad$ Girls show emotions, boy should fight back.

- Women liberation means higher access to leadership positions.

- $\quad$ Number one, big and fast are admirable.

- $\quad$ Religious differentiation of social roles of men and women.

On the other hand, low masculinity scores for both generations could be tied to the social welfare of the country and wealth of the people. It is the author's opinion that the social welfare system and wealth in the Gulf countries disengage youth from taking up challenges and participating in the contemporary economy. Actually, the fast economic development in the Gulf countries led the nations to be largely dependent on Western expertise in order to build a competitive modern nation as the case in the UAE and Qatar. Finally, it should be noted that 
three of undergraduate students who took part on this survey approached the author two days after administering the questionnaires indicating that question five "live in a desirable area" and question eight "have pleasant people to work with" on the original questionnaire made no sense to Emirati culture and environment. This intervention from the participants could be interpreted that some items of the measurement instrument should be adapted to the surveyed population to get clear results.

\section{Emirati Uncertainty Avoidance Index}

The younger and older generations of the UAE, as represented by the study sample score low on uncertainty avoidance. Younger generation scores 19.18 and the older generation scores 27.59 , which suggests that there is a fair degree of acceptance for new ideas, innovative products and willingness to try the newly introduced technology and products in education, health and social sectors. Interestingly, both generations tend to be more tolerant of the newness, and do not feel threatened by ambiguity as indicated earlier.

Low uncertainty avoidance is predicated by the author among the younger generation than the older one. Accordingly, the author highly stressed the history and religion as an interrelated factor to high uncertainty avoidance among the older generation because Islamic teachings teach absolute truths to its believers. Given the nature of the surveyed sample and the cultural profile of UAE University, the author argues that both generations are likely to score low on uncertainty avoidance because of the elite environment of the UAE that barrows the latest models and advanced technology from the West to be utilized by faculty, administrators and students.

UAEU environment highly encourages entrepreneurial activities and innovative scientific research among its population to go in line with the UAE Vision 2021 in transforming from an 
oil-based to a knowledge-based society that focuses on scientific research in the country, which effectively increase generational willingness to be more tolerant of the unknown and create the desired events instead of waiting for events to happen. Therefore, the author believes that surveying grandparents of the younger generation would be an ideal sample to compare and contrast the pre-oil era and the modern era of the country to determine the extent of value change and the significance difference between the current sixth generation and the second generation of the country.

\section{Emirati Long-Term Orientation Index}

The younger and older generations of the UAE, as represented by the study sample score low on long-term orientation. Younger generation scores 28.06 and the older generation scores 25.76, which suggests that both generations exhibit short-term orientation rather than pragmatic long-term orientation This confirms the predicated value of Emirati people, which is characterized by short-term orientation. UAE federal government is on a strategic move based on a thorough, future oriented competitive economy that mandates institutions, organizations and people of the country to further the UAE's global competitiveness in line with UAE's vision 2021 by lunching strategic plans to foster innovation and creativeness among the people of the country. The author believes that UAE's vision 2021 and its competitive economy labels UAE government as a future oriented country not its indigenous people. Unlike the government, the older and younger generations of the UAE are not future oriented. This is reflected on the sudden handed over wealth by the government and the welfare system in the country that resulted in lack of persistence and thrift among the Emirati people to take up greater responsibilities and contribute to the overall productivity and competitiveness. In the last decades, UAE government became largely dependent on foreign expertise to boost innovative-driven economy and overall 
prosperity in the nation, which disengaged Emiratis from participating in the race of excellence and competitiveness.

Moreover, Hofstede (2001) identifies a dominant correlation of LTO with economic growth and the top five countries are known for their fast economic growth. Therefore, the author believes that the UAE millennial generation, who are active participants in the UAE contemporary economy, will be becoming more future-oriented in the next decades for survival and inclusion purposes.

\section{UAE Society Contradictory Results}

Surprisingly, the new obtained data from UAE University sample does not replicate some of the rankings that are registered in Hofstede's IBM original data. Scores for power distance, masculinity and uncertainty avoidance are lower than indicated by the literature, while low individualism is almost similar. Overall, the obtained results are way different from those reported by Hofstede, which led the author to explain and examine the specific characteristics of the sample and the systematic value change in relation to the seemingly contradictory results in the study.

The literature categorizes the Arab countries as a combination of high scores on power distance and uncertainty avoidance, and low scores on individualism index. Recent studies on the Arab world suggest that the region is very heterogeneous in nature than Hofstede's work leads us to believe, particularly the oil rich countries. Oshlyansky, Cairns and Thimbleby (2006) surveyed a student sample in Saudi Arabia using VSM94, which indicates similar results only on power distance and long-term orientation dimensions of our own study than what registered by Hofstede. Similarly, Carl, Gupta, and Javidan (2004) work, which is part of GLOBE study report some systematic value change among different countries in the Arab world overtime. These 
studies provide support to the hypothesis of value change overtime, and suggest the heterogeneous nature of the Arab world in which cultural dimensions are not as widely generalizable as previously believed.

Another factor would be the specific characteristics of the sample. Faculty, administrators, and students are part of an elite educational environment in which Western influence and status might have a cognitive effect on participants' responses while responding to the study questionnaires. As indicated in the methodology section, all administrators are alumni of UAE University and all national faculty members obtained their doctoral degrees from North American and British higher education institutions. Thus, the author cautiously suggests a sample bias in terms of age, education level and environment between both generations that led to the contradictory results.

\section{Limitations}

This study on generational differences in the UAE has certain limitations. The choice of population and organization is a possible sample bias because the study does not employ a comparison group who are parts of the UAE society, governmental institutions and private organizations. UAE University is an elite educational environment, and respondents are subjects to Western influence. Therefore, it is not possible to generalize these findings to the entire nation of the United Arab Emirates, but it could be a representation of higher education cultural profile of the Gulf countries, which are highly influenced by North American higher educations systems.

Another possible limitation might be the presence of Western bias in some of the questions of the VSM08, in particular Masculinity index in which some of questions do not make sense in the context of Emirati culture. Furthermore, the majority of sample population is 
undergraduate female students who are drawing their responses from anticipation than an actual work experience. Lack of published publications on UAE's social practices and attitudes led the author to rely on her experience and conscious observations to draw such a conclusion and hypothesis with an advantage of being an Emirati who are born, raised and educated in the indigenous culture.

Despite these limitations, the obtained results are very important data for illustrating cultural change in a fast-developing economy and a young nation of four decades. This study yields an important glimpse on the cultural profile of higher education institutions in the Gulf region and generational differences or similarities in the context of rapid economic and cultural shifts and demographic imbalance.

\section{Contributions and Significance}

The aim of this study was to explore changes in leadership cultural values among two generations in United Arab Emirates. The study conducted a straightforward administration of Hofstede's VSM08 questionnaire along with demographic cultural profile of respondents in order to examine differences, and capture generational struggles to adopt in an oil rich country of desert history and traditional values, yet largely Westernized society. The author hypothesized a generational difference as per some of the cultural values on Hofstede's five dimensions in the context of rapid economic development and cultural shift. The further purpose of the study questionnaire was to fully understand the dynamic societal and value change in rapidly developing societies as is the case in the UAE.

Interesting observations and results were deduced from this research study that contradicted Hofstede's scores on power distance, masculinity and uncertainty avoidance showed no significant differences on the three above mentioned dimensions as represented by 
the study sample. The new indices of the UAE and the similar indices' scores of two generations triggers a further identifications of factors that informed the current results.

Wealth and abundant life is believed by the author to be the primary influencing predicator for the registered index scores. Wealth in the UAE can be interpreted as: abundant life, technological advancements, higher quality of education and health services, tourism industry, intercultural communication and cooperation, and fertile environment for world business headquarters. It has been observed from the index scores that the abundant life in the country is highly welcomed and accepted by almost every member of the UAE society. Distribution of wealth and high quality of the social welfare system in the country probably affects the extent Emiratis perceive wealth distribution (low power distance), quality of life and gender roles (femininity) in the UAE contemporary society.

Moreover, the findings suggest generational struggles between the present espoused values and the traditional Islamic values of Emiratis. The author is still surprised by the results of both generations that reveal no significant differences and contradict Hofstede's original data of IBM that was collected 30 years ago. The results could be interpreted as a systematic value change and on the other hand it could be seen as a wide acceptance to live and behave in opposing values to survive under great Western influence that was brought by the rapid economic developments.

\section{Future Directions}

Further research is needed to investigate systematic value change between the pre-oil generation and the younger generation of the UAE who belongs to different societal and institutional groups to check for a sample bias and indicate differences in the obtained index scores. It would be also interesting to survey Non-Emirati residents and compare the indices of 
both indigenous and expertise population in the country.

In the context of rapid social and economic changes, much research is needed to fully understand the conflicting values of traditions and Westernization in the life of young Emirati who are going to socialize the future generations of the UAE. Conducting interviews and focus groups with members of different generations would also considerably enrich our knowledge of the changes in UAE society and culture and help explain their sources. Finally, additional changes on VSM08 should be made to include some related question to the belief systems of the country and other Gulf countries, which considers Islam, traditions, sudden wealth as a dominant factors in unveiling the cultural profiles of these countries, and the differences between them. A qualitative approach would be much appreciated to understand the underlying beliefs of the nation's cultural mindsets. Having emphasized the importance of understanding the nation's mental software in a multidimensional generational phenomenon, the author proposes a more extensive qualitative narrative of the pre-oil generation of the UAE to enrich the existing literature and clarify the extent of value change in fast-developing Bedouin societies. 


\section{References}

Adler, N. (2002). International dimensions of organizational behavior (4th ed.). Cincinnati, OH: Southwestern Publishing.

Al Fahim, M. (1995). From rags to riches: A story of Abu Dhabi. London: London Centre of Arab Studies.

Al-Khouri, A. (June, 2010). The challenge of identity in a changing world: The case of GCC countries. Paper presented at Gulf Studies Conference, Exeter, England.

Al-Majaida, J. (2002). The press and social change in the United Arab Emirates: 1971-199. Abu Dhabi: Zayed Center for Coordination \& Follow-Up.

Al-Sayegh, F. (1998). Merchants' role in a changing society: The case of Dubai, 1900-90. Middle Eastern Studies, 34 (1), 87-102.

Al-Sayegh, F. (2004). Post-9/11 changes in the gulf: The case of the UAE. Middle East Policy, $11(2), 107-124$.

Twitter in the Arab Region. (2014, April 28). Arab Social Media Report (ASMR). Retrieved from http://www.arabsocialmediareport.com/home/index.aspx

Armer, J. M., \& Katsillis, J. (1992). Modernization theory. Encyclopedia of Sociology, 3, 12991304.

Ayish, M. I. (2010). Arab State Broadcasting Systems in Transition The Promise of the Public Service Broadcasting Model. Middle East Journal Of Culture \& Communication, 3(1), 925. doi:10.1163/187398609X12584657078448

Baharoon (March, 2012). Identity and Society in the UAE: A Discourse on Synergy Paper 7th 
Global Conference on Pluralism, Inclusion and Citizenship, Prague, Czech Republic. Retrieved from http://www.inter-disciplinary.net/at-the-interface/diversityrecognition/pluralism- inclusion-and-citizenship/steering-group/7th/session-3-media-andnetworks/

Bohner, G., \& Wänke, M. (2002). Attitudes and attitude change. Psychology Press.

Brewer, P., \& Venaik, S. (2010). GLOBE practices and values: A case of diminishing marginal utility\&quest. Journal of international business studies, 41(8), 1316-1324.

Bristol-Rhys, J. (2010). Emirati Women: Generations of Change. London: Hurst.

Carl, D., Gupta, V., \& Javidan, M. (2004). Power distance. In R. J. House, P. J. Hanges, M. Javidan, P. W. Dorfman \& V. Gupta (Eds.), Culture, leadership, and organizations: The GLOBE study of 62 societies (pp. 513- 563). Thousand Oaks, CA: Sage.

Christie, P. M. J., Kwon, I. G., Stoeberl, P. A., \& Baumhart, R. (2003). A Cross-Cultural Comparison of Ethical Attitudes of Business Managers: India, Korea and the United States. Journal of Business Ethics, 46, 263-287.

Cole, D. P. (2003). Where have the Bedouin gone?. Anthropological Quarterly, 76(2), 235-267.

Crocetti, G. L., \& Benesh, G. C. (1996). Culture Shock! United Arab Emirates. Graphic Arts Books.

Dahl, S. (2004). Intercultural Research: The Current State of Knowledge. Middlesex University Business School Discussion Paper, London. Retrieved from http://bjoern.releasemyalbum.com/literature/DahlS_2004_Intercultural\%20researchThe $\% 20$ current $\% 20$ state $\% 20$ of $\% 20$ knowledge Middlesex $\% 20$ University Discussion $\% 2$ OPaper_No26.pdf

De Mooij, M. (2010). Consumer behavior and culture: Consequences for global marketing and 
advertising. Sage.

Dhaheri, H. (2009). Women and Nation Building: The Case of the United Arab Emirates. Hawwa, 7 (3): 271-302.

Dunivin, K. O. (1994). Military culture: Change and continuity. Armed Forces \& Society, 20(4), $531-547$.

El-Aswad, E. S. (2005). United Arab Emirates. Religious Rituals and Folk Theater in Muslim Societies: A Comparative Study.

Emirates News Agency. (2014, September $3^{\text {rd }}$ ). UAE jumps 7 positions on the World Economic Forum's Global Competitiveness Report. WAM. Retrieved from http://www.wam.ae/en/news/emirates-international/1395269176197.html

Fenelon, K. G. (1976). The United Arab Emirates: an economic and social survey. Longman Publishing Group.

Findlow, S. (2005). International networking in the United Arab Emirates higher education system: global-local tensions. Compare: A Journal of Comparative and International Education, 35(3), 285-302.

Frey, F. W. (1970). Cross-cultural survey research in political science. Human Factors in Modernization Project, Center for International Studies, MIT.

Geertz. C. (1973). The interpretation of culture: Selected essays. New York: Basic Books. Goode, W. J. (1963). World revolution and family patterns. New York: The Free Press.

Graves, D. (1986). Corporate Culture - Diagnosis and Change: Auditing and changing the culture of organizations. London, Frances Printer.

Groseschl, S., \& Doherty, L. (2000). Conceptualising culture. Cross cultural management: an international journal, 7(4), 12-17. 
Hawley, D. (2007). The Emirates: witness to a metamorphosis. Michael Russell.

Hawley, D. (1970). The Trucial States. London: Allen \& Unwin.

Heard-Bey, F. (2005). The United Arab Emirates: Statehood and nation-building in a traditional society. The Middle East Journal, 357-375.

Hofstede, G. (2001) Culture's Consequences: Comparing values, behaviors, institutions, and organizations across nations - 2nd Ed. Sage Publications, London, England

Hofstede, G., Hofstede, G. J., Minkov, M., \& Vinken, H. (2008). Values Survey Module 2008 Manual. Geert Hofstede BV. Retrieved from http://stuwww.uvt.nl/\%7Ecsmeets/ManualVSM08.doc

House R., Javidan M., Hanges P., Dorfman, P., Dastmalchian, A. (2012). GLOBE: A twenty year journey into the intriguing world of culture and leadership. Journal of World Business 47. 504-518.

House, R.J., Hanges, P.J., Javidan, M. Dorfman, P., \& Gupta, V. (2004). Leadership, culture, and organizations: The GLOBE study of 62 societies. Thousand Oaks, CA: Sage Publications, Inc.

Inkeles, A. (1977). Continuity and change in the American national character. Paper prepared for the annual meeting of the American Sociological Association, Chicago.

Inkeles, A., \& Smith, D. (1974). Becoming modern. Cambridge: Harvard University Press. Jawad, H.A. (1998). The Rights of women in Islam: an authentic approach. New York: St. Martin's Press.

Jones, M. L. (2007). Hofstede-culturally questionable?. Retrieved from http://ro.uow.edu.au/cgi/viewcontent.cgi?article=1389\&context=commpapers

Karahanna, E., Evaristo, J., and Srite, M. (2005). Levels of Culture and Individual Behaviour: 
An Integrative Perspective, Journal of Global Information Management, 13(2): 1-20.

Khelifa, M. (2010). Trading Culture: Have Western-educated Emirati Females Gone Western?. OIDA International Journal of Sustainable Development, 1(3), 19-29.

Khoury, P. S., \& Kostiner, J. (Eds.). (1990). Tribes and state formation in the Middle East. University of California Press.

Koch, C. (2011). Economic Trumps Politics in the United Arab Emirates. Mary Ann Tetreault, Gwenn Okruhlik, and Andrzej Kapiszewski eds, Political Change in the Arab Gulf States: Stuck in Transition. Boulder and London: Lynne Rinner, 167-189.

Kour, Z. H. (1991). The states of Arabia. New Delhi: Vikas Publishing House.

Maseland, R., \& Van Hoorn, A. (2009). Explaining the negative correlation between values and practices: A note on the Hofstede-GLOBE debate. Journal of International Business Studies, 40(3), 527-532.

McSweeney, B. (July, 2000). The Fallacy of National Culture Identification. In 6th Interdisciplinary Perspectives on Accounting Conference. Manchester, UK.

Mills, A. (2008). Emirates look to the West for prestige. Chronicle of Higher Education, 55(5),A1.

Minkov, M. (2007). What makes us different and similar: A new interpretation of the World Values Survey and other cross-cultural data. Klasika i Stil Publishing House.

Minkov, M., Hofstede, G., Hofstede, G. J.,., Vinken, H., (2008) Values Survey Module VSM 08 Handbook. Retrieved from http://www.geerthofstede.nl

Murphy, E. C. (2009). Theorizing ICTs in the Arab world: Informational capitalism and the public sphere. International Studies Quarterly, 53(4), 1131-1153.

Nasif, E. G., Al-Daeaj, H., Ebrahimi, B., \& Thibodeaux, M. S. (1991). Methodological problems 
in cross-cultural research: An updated review. MIR: Management International Review,79-91.

National Editor. (2015, February 9). UAE leaders attend Government Summit in Dubai. The National. Retrieved from http://www.thenational.ae/uae/government/uae-leaders-attendgovernment-summit-in-dubai---in-pictures

National Editorial. (2015, February 10). Sheikh Mohammed bin Zayed's inspirational vision for a post-oil UAE. The National. Retrieved from http://www.thenational.ae/opinion/editorial/sheikh-mohammed-bin-zayeds-inspirationalvision-for-a-post-oil-uae

Nisbet, E. C., \& Myers, T. A. (2010). Challenging the state: Transnational TV and political identity in the Middle East. Political Communication, 27(4), 347-366.

Olie, R. (1995) The culture factor in personnel and organization policies. In: Harzing, A- W., and Ruysseveldt, J. V. (eds) (1995) International Human Resource Management. Sage Publications. London. 124-143.

Onley, J., \& Khalaf, S. (2006). Shaikhly Authority in the Pre-oil Gulf: An HistoricalAnthropological Study. History and Anthropology, 17(3), 189-208.

Oshlyansky, L., Cairns, P., \& Thimbleby, H. (September, 2006). A cautionary tale: Hofstede's VSM revisited. In Proceedings of the 20th BCS HCI Group Conference (Vol. 2, pp. 11$15)$.

Peterson, J. E. (2009). Britain and the Gulf: at the periphery of Empire. The Persian Gulf in History, 279-281.

Rugh, A. B. (2007). The Political Culture of Leadership in the United Arab Emirates. New York: Palgrave Macmillan. 
Russell, A., Coughlin, C., El Walily, M., \& Al Amri, M. (2005). Youth in the United Arab Emirates: Perceptions of problems and needs for a successful transition to adulthood. International Journal of Adolescence and Youth, 12(3), 189-212.

Schvaneveldt, P. L., Kerpelman, J. L., \& Schvaneveldt, J. D. (2005). Generational and cultural changes in family life in the United Arab Emirates: A comparison of mothers and daughters. Journal of Comparative Family Studies, 77-91.

Shaw, K. (1997). Higher education in the gulf: problems and prospects. Exeter: University of Exeter Press. 1-15

Sivakumar, K., \& Nakata, C. (2001). The stampede toward Hofstede's framework: Avoiding the sample design pit in cross-cultural research. Journal of international business studies, $555-574$.

Søndergaard, M. (1994). Hofstede's consequences: A study of reviews, citations and replications. Organizational Studies 15(3): 447.

Tapper, R. (1990). Anthropologists, historians, and tribespeople on tribe and state formation in the Middle East. Tribes and state formation in the Middle East, 48-73.

Tayeb, M. (2001). Conducting Research Across Cultures: Overcoming Drawbacks and Obstacles. International Journal of Cross Cultural Management, 1(1), 91-108.

The Government Summit. (2013, February 11). E-First Government Summit Proceeding Report. Retrieved from https://www.thegovernmentsummit.org/EventFolder/KnowledgeHubFolder/KnowledgeH ub_6/GS13-Report EN.pdf

Triandis, H. C. (1972). The analysis of subjective culture. New York: John Wiley \& Sons. Trompenaars, F., \& Hampden-Turner, C. (1997). Riding the waves of culture: understanding 
cultural diversity in business, Nicholas Brealy. London, England.

UAENEC (United Arab Emirates National Election Committee). (2011, June 2nd). About FNC Election UAENEC. Retrieved from http://www.uaenec.ae/en/about-us/about-fncelections.aspx

Willemyns, M. (2008). The rapid transformation of Emirati managers' values in the United Arab Emirates. Retrieved from http://ro.uow.edu.au/dubaipapers/137

Zahlan, R. S. (1998). The Making of the Modern Gulf States: Kuwait, Bahrain, Qatar, the United Arab Emirates and Oman. Reading: Ithaca Press 


\title{
Appendix A
}

\author{
V S M 08 \\ VALUES SURVEY MODULE 2008 \\ QUESTIONNAIRE \\ English language version
}

Release 08-01, January 2008

Copyright@Geert Hofstede BV

hofstede@,bart.nl; www.geerthofstede.nl 


\section{INTERNATIONAL QUESTIONNAIRE (VSM 08)- page 1}

Please think of an ideal job, disregarding your present job, if you have one. In choosing an ideal job, how important would it be to you to ... (please circle one answer in each line across):

$$
\begin{aligned}
& 1=\text { of utmost importance } \\
& 2=\text { very important } \\
& 3=\text { of moderate importance } \\
& 4=\text { of little importance } \\
& 5=\text { of very little or no importance }
\end{aligned}
$$

01. have sufficient time for your personal or home life

$$
\begin{array}{lllll}
1 & 2 & 3 & 4 & 5
\end{array}
$$

02. have a boss (direct superior) you can respect

$\begin{array}{lllll}1 & 2 & 3 & 4 & 5\end{array}$

03. get recognition for good performance

04. have security of employment $\begin{array}{lllll}1 & 2 & 3 & 4 & 5\end{array}$

05. have pleasant people to work with $\begin{array}{lllll}1 & 2 & 3 & 4 & 5\end{array}$

06. do work that is interesting $\begin{array}{lllll}1 & 2 & 3 & 4 & 5\end{array}$

07 . be consulted by your boss in decisions involving your work

$\begin{array}{lllll}1 & 2 & 3 & 4 & 5\end{array}$

08. live in a desirable area $\begin{array}{lllll}1 & 2 & 3 & 4 & 5\end{array}$

09. have a job respected by your family and friends

$\begin{array}{lllll}1 & 2 & 3 & 4 & 5\end{array}$

10. have chances for promotion

$\begin{array}{lllll}1 & 2 & 3 & 4 & 5\end{array}$

In your private life, how important is each of the following to you: (please circle one answer in each line across):

11. keeping time free for fun

12. moderation: having few desires

13. being generous to other people

14. modesty: looking small, not big $\begin{array}{lllll}1 & 2 & 3 & 4 & 5\end{array}$

$\begin{array}{lllll}1 & 2 & 3 & 4 & 5\end{array}$

$\begin{array}{lllll}1 & 2 & 3 & 4 & 5\end{array}$

$\begin{array}{lllll}1 & 2 & 3 & 4 & 5\end{array}$




\section{INTERNATIONAL QUESTIONNAIRE (VSM 08) - page 2}

15. If there is something expensive you really want to buy but you do not have enough money, what do you do?

1. always save before buying

2. usually save first

3. sometimes save, sometimes borrow to buy

4. usually borrow and pay off later

5. always buy now, pay off later

16. How often do you feel nervous or tense?

1. always

2. usually

3. sometimes

4. seldom

5. never

17. Are you a happy person?

1. always

2. usually

3. sometimes

4. seldom

5. never

18. Are you the same person at work (or at school if you're a student) and at home?

1. quite the same

2. mostly the same

3. don't know

4. mostly different

5. quite different

19. Do other people or circumstances ever prevent you from doing what you really want to?

1. yes, always

2. yes, usually

3. sometimes

4. no, seldom

5. no, never

20. All in all, how would you describe your state of health these days?

1 . very good

2. good

3. fair

4. poor

5. very poor

21. How important is religion in your life?

1. of utmost importance

2. very important

3. of moderate importance

4. of little importance

5. of no importance 


\section{INTERNATIONAL QUESTIONNAIRE (VSM 08) - page 3}

22. How proud are you to be a citizen of your country?

1. not proud at all

2. not very proud

3. somewhat proud

4. fairly proud

5. very proud

23. How often, in your experience, are subordinates afraid to contradict their boss (or students their teacher?)
1. never
2. seldom
3. sometimes
4. usually
5. always

To what extent do you agree or disagree with each of the following statements? (please circle one answer in each line across):

$$
\begin{aligned}
& 1=\text { strongly agree } \\
& 2=\text { agree } \\
& 3=\text { undecided } \\
& 4=\text { disagree } \\
& 5=\text { strongly disagree }
\end{aligned}
$$

24. One can be a good manager without having a precise answer to every question that a subordinate may raise about his or her work

$$
\begin{array}{lllll}
1 & 2 & 3 & 4 & 5
\end{array}
$$

25. Persistent efforts are the surest way to results

$$
\begin{array}{lllll}
1 & 2 & 3 & 4 & 5
\end{array}
$$

26. An organization structure in which certain subordinates have two bosses should be avoided at all cost

$\begin{array}{lllll}1 & 2 & 3 & 4 & 5\end{array}$

27. A company's or organization's rules should not be broken not even when the employee thinks breaking the rule would be in the organization's best interest

28. We should honour our heroes from the past

$\begin{array}{lllll}1 & 2 & 3 & 4 & 5\end{array}$




\section{INTERNATIONAL QUESTIONNAIRE (VSM 08)- page 4}

Some information about yourself (for statistical purposes):

29. Are you:
1. male
2. female

30. How old are you?

1. Under 20

2. $20-24$

3. $25-29$

4. $30-34$

5. $35-39$

6. $40-49$

7. $50-59$

8. 60 or over

31. How many years of formal school education (or their equivalent) did you complete (starting with primary school)?
1. 10 years or less
2. 11 years
3. 12 years
4. 13 years
5. 14 years
6. 15 years
7. 16 years
8. 17 years
9. 18 years or over

32. Which Emirate:
1. Abu Dhabi
2. Dubai
3. Sharjah
4. Ajman
5. Ras al-Khaimah
6. Fujairah
7. Umm al Quwain

33. If you have or have had a paid job, what kind of job is it / was it?

1. No paid job (includes full-time students)

2. Unskilled or semi-skilled manual worker

3. Generally trained office worker or secretary

4. Vocationally trained craftsperson, technician, IT-specialist, nurse, artist or equivalent

5. Academically trained professional or equivalent (but not a manager of people)

6. Manager of one or more subordinates (non-managers)

7. Manager of one or more manager 


\section{INTERNATIONAL QUESTIONNAIRE (VSM 08)- page 5}

34. If you are a student:

1. Major:

2. Year:

3. College

35. Non-student occupation:

1. Administrator:

Department

Years at University

2. Faculty:

Department

Years of experience

36. What is your nationality?

37. What was your nationality at birth (if different)?

Thank you very much for your cooperation! 


\section{Appendix B}

\section{Social Sciences Research Ethics Committee -Approval-}

$\begin{array}{ll}\text { Title of Project: } & \begin{array}{l}\text { Leadership Cultural Dimensions of the United Arab Emirates - The Case } \\ \text { of United Arab Emirates University }\end{array} \\ \text { PI: } & \text { Ebtesam Ali Alteneiji } \\ \text { Co-PI (if any) } & \end{array}$

The above proposal has been reviewed by:

$\square \quad$ all the five members of the Social Sciences REC

$凶$ three members of the Social Sciences REC (Proportionate Review)

And the decision is:

囚 Favourable

$\square$ Favourable with Additional Conditions

$\square$ Provisional Opinion

$\square$ Unfavourable Opinion

$\square$ No Opinion (Proportionate Review* only)

Name

(Chair or designee):

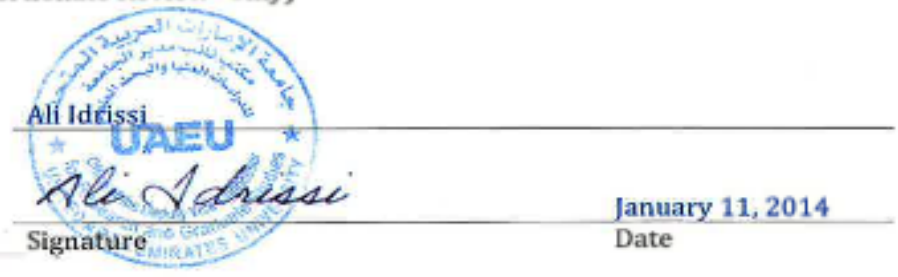

The decisions available to the Committee are defined as follows:

"Favourable with standard conditions" means that the study has ethical approval to proceed, as long as local management approval is in place prior to the study starting.

"Favourable with Additional Conditions" means that the study has ethical approval in principle but there are certain issues which need to be addressed prior to the study 


\section{Appendix C}

\section{Calculating the Five Dimensions' Indices}

All content questions are scored on five-point scales $(1,2,3,4,5)$. Index scores are derived from the mean scores on the questions of Hofstede's VSM08 for two samples of respondents. The formulas and calculations are the ones designed and used in Hofstede's VSM08 (2008):

\section{Power Distance Index Formula:}

$$
\text { PDI }=35(\mathrm{~m} 07-\mathrm{m} 02)+25(\mathrm{~m} 23-\mathrm{m} 26)+\mathrm{C}(\mathrm{pd})
$$

In which $\mathrm{m} 07$ is the mean score for question 07 as numbered in Hofstede's VSM08 questionnaire, etc. The index will normally have a value range between 0 very small power distance to 100 very large power distance. $\mathrm{C}(\mathrm{pd})$ is a positive or negative constant that depends on the nature of the samples. It can be chosen by the researcher to shift PDI scores to values between 0to 100 .

The formula showing the new question numbers for the younger generation as they appeared in Excel sheet:

$$
\begin{aligned}
& \mathrm{PDI}=35 *(\mathrm{H} 83-\mathrm{C} 83)+25 *(\mathrm{X} 83-\mathrm{AA} 83) \\
& \mathrm{PDI}=35(1.75-1.46)+25 *(3.51-2.16) \\
& \mathrm{PDI}=43.67
\end{aligned}
$$

The formula showing the new question numbers for the older generation as they appeared in Excel sheet:

$\mathrm{PDI}=35 *(\mathrm{H} 54-\mathrm{C} 54)+25 *(\mathrm{X} 54-\mathrm{AA} 54)$

$\mathrm{PDI}=35 *(1.96-1.53)+25 *(3.11-1.80)$

$\mathrm{PDI}=47.5$

This results show that the younger generation scores lower on power distance than the older, but both of them generally score medium on the power distance index.

\section{Individualism Index Formula:}

$$
\mathrm{IDV}=35(\mathrm{~m} 04-\mathrm{m} 01)+35(\mathrm{~m} 09-\mathrm{m} 06)+\mathrm{C}(\mathrm{ic})
$$

The formula showing the new question numbers for the younger generation as they appeared in Excel sheet:

$$
\begin{aligned}
& \mathrm{IDV}=35 *(\mathrm{E} 83-\mathrm{B} 83)+35 *(\mathrm{~J} 83-\mathrm{G} 83) \\
& \mathrm{IDV}=35^{*}(1.67-1.55)+35 *(1.91-1.51) \\
& \mathrm{IDV}=18.57
\end{aligned}
$$

The formula showing the new question numbers for the older generation as they appeared in Excel sheet:

$\mathrm{IDV}=35 *(\mathrm{E} 54-\mathrm{B} 54)+35 *(\mathrm{~J} 54-\mathrm{G} 54)$

$\mathrm{IDV}=35 *(2.01-1.65)+35 *(1.78-1.63)$

$\mathrm{IDV}=18$

Both generations score low on individualism .. collective society

\section{Masculinity Index Formula:}

$$
\mathrm{MAS}=35(\mathrm{~m} 05-\mathrm{m} 03)+35(\mathrm{~m} 08-\mathrm{m} 10)+\mathrm{C}(\mathrm{mf})
$$

The formula showing the new question numbers for the younger generation as they appeared in Excel sheet:

$$
\begin{aligned}
& \text { MAS }=35 *(\mathrm{~F} 83-\mathrm{D} 83)+35 *(\mathrm{I} 83-\mathrm{K} 83) \\
& \mathrm{MAS}=35^{*}(1.38-1.44)+35 *(1.91-1.34) \\
& \mathrm{MAS}=17.85
\end{aligned}
$$


The formula showing the new question numbers for the older generation as they appeared in Excel sheet:

$$
\begin{aligned}
& \text { MAS }=35 *(\text { F54-D54 })+35 *(\text { I54-K54 }) \\
& \text { MAS }=35 *(1.65-1.63)+35 *(1.96-1.61) \\
& \text { MAS }=12.78
\end{aligned}
$$

\section{Uncertainty Avoidance Index Formula:}

$$
\mathrm{UAI}=40(\mathrm{~m} 20-\mathrm{m} 16)+25(\mathrm{~m} 24-\mathrm{m} 27)+\mathrm{C}(\mathrm{ua})
$$

The formula showing the new question numbers for the younger generation as they appeared in Excel sheet:

$$
\begin{aligned}
& \mathrm{UAI}=40(\mathrm{U} 83-\mathrm{Q} 83)+25(\mathrm{Y} 83-\mathrm{AB} 83)+\mathrm{C}(\mathrm{ua}) \\
& \mathrm{UAI}=40 *(1.79-2.65)+25 *(3.20-2.26)+30 \\
& \mathrm{UAI}=19.18
\end{aligned}
$$

The formula showing the new question numbers for the older generation as they appeared in Excel sheet:

$$
\begin{aligned}
& \mathrm{UAI}=40(\mathrm{U} 54-\mathrm{Q} 54)+25(\mathrm{Y} 54-\mathrm{AB} 54)+\mathrm{C}(\mathrm{ua}) \\
& \mathrm{UAI}=40 *(1.88-2.75)+25 *(3.26-1.98)+30 \\
& \mathrm{UAI}=27.59
\end{aligned}
$$

\section{Long-Term Orientation Index Formula:}

$$
\mathrm{LTO}=40(\mathrm{~m} 18-\mathrm{m} 15)+25(\mathrm{~m} 28-\mathrm{m} 25)+\mathrm{C}(\mathrm{ls})
$$

The formula showing the new question numbers for the younger generation as they appeared in Excel sheet:

$$
\begin{aligned}
& \mathrm{LTO}=40 *(\mathrm{~S} 83-\mathrm{P} 83)+25 *(\mathrm{AC} 83-\mathrm{Z} 83) \\
& \mathrm{LTO}=40 *(2.73-1.91)+25 *(1.28-1.46) \\
& \mathrm{LTO}=28.06
\end{aligned}
$$

The formula showing the new question numbers for the older generation as they appeared in Excel sheet:

$\mathrm{LTO}=40 *(\mathrm{~S} 54-\mathrm{P} 54)+25 *(\mathrm{AC} 54-\mathrm{Z} 54)$

$\mathrm{LTO}=40 *(2.53-1.65)+25 *(1.48-1.86)$

$\mathrm{LTO}=25.76$ 